\title{
Improved Adhesion and Tribological Properties of AlTiN-TiSiN Coatings Deposited by DCMS and HiPIMS on Nitrided Tool Steels
}

\author{
Adrián Claver ${ }^{1,2, *}$, Jesús J. Randulfe ${ }^{1}$, José F. Palacio ${ }^{3} \mathbb{D}$, Jonathan Fernández de Ara ${ }^{3}(D)$ Eluxka Almandoz ${ }^{3}(\mathbb{D}$, \\ Francesc Montalá ${ }^{4}$, Carles Colominas ${ }^{4}$, Victor Cot $^{4}$ and Jose A. García ${ }^{1,2}$ (D) \\ 1 Engineering Department, Public University of Navarre (UPNA), Campus de Arrosadía S/N, \\ 31006 Pamplona, Spain; jrandulfeceballos@yahoo.es (J.J.R.); joseantonio.garcia@unavarra.es (J.A.G.) \\ 2 Institute for Advanced Materials and Mathematics (INAMAT2), Public University of Navarre (UPNA), \\ Campus de Arrosadia, 31006 Pamplona, Spain \\ 3 Centre of Advanced Surface Engineering, AIN, 31191 Cordovilla, Spain; jfpalacio@ain.es (J.F.P.); \\ jfernandez@ain.es (J.F.d.A.); ealmandoz@ain.es (E.A.) \\ 4 FLUBETECH, S.L., c $\backslash$ Montsià, 23 Pol. Ind. Can Carner, 08211 Castellar del Vallès, Spain; \\ francesc.montala@flubetech.com (F.M.); carles.colominas@flubetech.com (C.C.); \\ victor.cot@flubetech.com (V.C.) \\ * Correspondence: adrian.claver@unavarra.es; Tel.: +34-676-927-082
}

Citation: Claver, A.; Randulfe, J.J.; Palacio, J.F.; Fernández de Ara, J.; Almandoz, E.; Montalá, F.; Colominas, C.; Cot, V.; García, J.A. Improved Adhesion and Tribological Properties of AlTiN-TiSiN Coatings Deposited by DCMS and HiPIMS on Nitrided Tool Steels. Coatings 2021, 11, 1175. https://doi.org/10.3390/ coatings11101175

Academic Editor:

Diego Martinez-Martinez

Received: 3 September 2021

Accepted: 24 September 2021

Published: 28 September 2021

Publisher's Note: MDPI stays neutral with regard to jurisdictional claims in published maps and institutional affiliations.

Copyright: (c) 2021 by the authors. Licensee MDPI, Basel, Switzerland. This article is an open access article distributed under the terms and conditions of the Creative Commons Attribution (CC BY) license (https:// creativecommons.org/licenses/by/ $4.0 /)$.

\begin{abstract}
Hard coatings, such as AlTiN-TiSiN, deposited by Physical Vapor Deposition (PVD) techniques are widely used in industrial applications to protect and increase the lifetime of industrial components, such as cutting tools, dies, and forming tools. Despite their great properties, such as high hardness and wear and oxidation resistance, they are limited in cases of severe conditions due to the poor adhesion between the coating and the substrate. Duplex treatments have commonly been used to improve the adhesive properties of PVD coatings, especially those of the cathodic arc evaporation type. The purpose of this study is to achieve coatings with the good properties of the Magnetron Sputtering processes but with higher adhesion than that achieved with these techniques, thus achieving coatings that can be used under the most severe conditions. In this work, an AlTiN-TiSiN coating was deposited by a combination of DC Magnetron Sputtering (DCMS) and High-Power Impulse Magnetron Sputtering (HiPIMS) after a gas nitriding pretreatment on 1.2379 and Vanadis 4 tool steels. Mechanical (ultra-microhardness and scratch tests) and tribological tests were carried out to study the improvement in the properties of the coating. Duplex-treated samples showed improved adhesion between the coating and the substrate, with second critical load (Lc2) values greater than $100 \mathrm{~N}$. Furthermore, they showed great toughness and wear resistance. These results show that this type of coating technique could be used in the most extreme applications and that they can compete with other techniques and coatings that to date they have not been able to compete with.
\end{abstract}

Keywords: duplex; adhesion; hard coatings; PVD coatings; tribology; magnetron sputtering

\section{Introduction}

Hard coatings have been widely used to protect and increase the lifetime of industrial components, such as cutting tools, dies, and forming tools. Their excellent properties, such as high hardness, toughness, good tribological properties, and wear and oxidation resistance, make them ideal for applications in which industrial components are under high and constant loads [1-3]. This family contains different coatings (e.g., AlTiN, TiN, $\mathrm{CrN}$, and $\mathrm{AlCrN}$ ), and the addition of metallic or non-metallic elements, such as $\mathrm{Ti}, \mathrm{Si}, \mathrm{Al}$, and $\mathrm{C}$, and the deposition parameters have a strong influence on their physical, chemical, and mechanical properties [4-6]. TiN-based films are very hard and have good tribological properties; however, they present problems at high temperatures due to their poor thermal 
stability and insufficient oxidation resistance [7-9]. Typically, oxidation starts at 450-500 ${ }^{\circ} \mathrm{C}$ in this type of coating $[7,10,11]$, so in dry machining they suffer from severe oxidation because the maximum temperature on the cutting edge is about $800-1000{ }^{\circ} \mathrm{C}$ [12-14]. In order to improve the oxidation resistance and thermal stability at high temperatures, $\mathrm{Al}$ can be incorporated into TiN films $[8,9,15]$, which can also contain $\mathrm{Si}$ in order to improve the hardness of the coating while keeping the thermal stability. However, the formation of a dense and protective $\mathrm{Al}_{2} \mathrm{O}_{3}$ layer would enhance the oxidation resistance of the coatings [16-18], but at temperatures above $850{ }^{\circ} \mathrm{C}$ the diffusion of Ti cations causes the appearance of micropores that lead to the loss of the protection against oxidation and the loss of the excellent mechanical properties $[7,19,20]$. So, TiAlN and TiSiN coatings are limited to industrial applications with a high degree of thermal exposure $[7,15]$. The addition of a fourth element to the coating and the application of multilayer coatings are two of the solutions that have been proposed to solve this problem $[15,21-24]$. On the one hand, different studies have proved that TiAlSiN coatings provide better properties in terms of hardness, oxidation resistance, and thermal stability than TiAlN coatings [22,25]. On the other hand, multilayer coatings have been widely used, to the detriment of monolayer films, due to their better mechanical and thermal properties and oxidation resistance [24,26,27]. Different studies have shown that TiSiN/TiAlN multilayer coatings have a higher hardness and lower friction coefficient than TiSiN and TiAlN monolayer coatings alone [7,24].

Despite their extraordinary properties, hard coatings do not always perform well enough in many applications under severe conditions. Bearing capacity and residual stresses are important factors to be considered in the protective performance of the coating [28]. Sometimes, the hardness of a coating is insufficient to withstand large cyclic mechanical loads, intensive thermal shocks, or high loads and eventually the substrate suffers from plastic deformation. In addition, if the substrate is soft and cannot carry the contact load, plastic deformation of the substrate will lead to premature failure of the coating [29]. This failure mechanism, which is caused by a hardness non-conformity, poor adhesion between the substrate and the coating, and a low bearing capacity, is a very common and important failure mechanism called "eggshell failure" [1,28,30].

Physical Vapor Deposition (PVD) and Chemical Vapor Deposition (CVD) techniques have been commonly used for depositing hard coatings [3,6,31]. Multilayer coatings deposited by magnetron sputtering have shown high oxidation resistance and high hardness [32,33], while cathodic arc plasma evaporation techniques have been widely used in industrial applications due to their better adhesive properties [24,34,35]. In addition, novel techniques such as HiPIMS [36] and hybrid arc and sputtering deposition [37] have been used to improve the properties of hard coatings. However, although PVD hard coatings can provide surfaces with improved tribological and mechanical properties, they cannot guarantee the correct performance of the system due to the importance of the plastic deformation resistance of the substrate that can lead to the failure of the coating [4,38-40].

As has already been mentioned above, under high applied loads plastic deformation of soft substrates would result in premature failure of the coating $[4,39]$. A frequently used solution to solve the adhesion problem is to apply a pretreatment that forms a thick and hard interlayer between the substrate and the coating, which results in a harder system, increases the load support effect of the substrate, and eliminates the stress concentration at the substrate-coating interface [41-44]. The combination of a thermochemical treatment and a posterior coating is known as a 'duplex treatment'.

According to this, duplex treatments that combine a nitriding pretreatment and PVD coatings are widely used to improve the adhesion of hard coatings to the substrate in casting, cutting, and forming tools [45-47]. During the plasma nitriding process, nitrogen atoms are diffused onto the surface, producing a modified layer with a high nitrogen concentration (the diffusion layer) and avoiding the compound layer (nitrides) at the outermost surface $[28,38]$. In this process, compressive stresses are formed in the nitrided zone that lead to an increase in the load-bearing capacity and the adhesion of the PVD coating [28]. 
The use of duplex PVD coatings for improving the adhesion of hard coatings has been reported in many studies [48-51]. Other novel techniques, such as HiPIMS with positive pulses [52] and closed-field unbalanced magnetron sputtering ion plating (CFUMSIP) [53], have also been used to improve the adhesion of PVD coatings in steel substrates. As reported in [49,50], duplex treatments based on plasma nitriding and magnetron sputtering showed critical scratch loads (Lc3) of about $60 \mathrm{~N}$ and $50 \mathrm{~N}$, respectively. On the other hand, high-velocity oxygen fuel (HVOF) spraying and PVD cathodic vacuum arc duplex treatments showed second critical scratch loads (Lc2) of around $55 \mathrm{~N}$ on steel substrates [54] and nitrocarburized and PVD cathodic multi-arc ion plating duplex treatments showed Lc2 values of about 50-57 N [4].

The aim of this study is to improve the adhesion and tribological properties of duplex treatments formed by gas nitriding and hard coatings deposited by magnetron sputtering techniques. To achieve the objective, AlTiN-TiSiN coatings were deposited by a combination of DC Magnetron Sputtering and HiPIMS after a gas nitriding pretreatment on 1.2379 and Vanadis 4 powder metallurgical (PM) tool steels. These materials were chosen due to their good properties and their great industrial applicability. This way, hard coatings with a good surface finish and the superior mechanical and tribological properties of magnetron sputtering techniques together with an improved adhesion that can compete with cathodic arc duplex treatments, which normally present better adhesion to the substrate, were studied. The adhesion of the coating to the substrate is essential to extend the useful life of tools, especially under conditions of extreme loads. So, the novelty of and motivation for this work is the improvement of the adhesion of the coatings using the HiPIMS technique and combining it with the gas nitriding pretreatment, thus improving the adhesion normally obtained with magnetron sputtering techniques and obtaining coatings that can compete with those deposited by the cathodic arc technique but that have the advantages of the magnetron sputtering techniques, e.g., a better surface finish.

\section{Materials and Methods}

\subsection{Reference Substrates}

The 1.2379 and Vanadis 4 (a brand-specific steel) tool steels with flat geometries and $30 \mathrm{~mm}$ diameters were used as reference substrates. The samples were polished $(\mathrm{Ra}<0.2 \mu \mathrm{m})$ and thoroughly cleaned before the surface treatments. The latter process consisted of ultrasonic washing with alkaline detergents (1\% Tickopurr R33) followed by rinsing with deionized water and isopropanol cleaning and finally air drying, respectively. The chemical composition of the materials is shown in Table 1.

Table 1. Chemical composition of the steels studied in this work (wt.\%).

\begin{tabular}{ccccccc}
\hline Steel & $\mathbf{C ~ ( \% )}$ & Si (\%) & Cr (\%) & V (\%) & Mn (\%) & Mo (\%) \\
\hline 1.2379 & 1.25 & 0.25 & 12 & 0.95 & 0.4 & 0.80 \\
Vanadis 4 & 1.4 & 0.4 & 4.7 & 3.7 & 0.4 & 3.5 \\
\hline
\end{tabular}

Both steels have extraordinary mechanical properties and are widely used in applications such as cutting, stamping, and forming tools, where the materials are subjected to high repetitive stresses; therefore, they must be hard and resistant to compression and they must have high wear resistance [55]. Vanadis 4 steel is of a higher quality than conventional steels since it is a powder metallurgical steel, which makes it have good dimensional stability and a finer carbide distribution than conventional steels, and it is free of segregations [55]. All these characteristics make it especially suitable for PVD treatments.

\subsection{Film Deposition Techniques}

The gas nitrocarburizing process was carried out at $500-520^{\circ} \mathrm{C}$ in an atmosphere rich in ammonia gas $\left(\mathrm{NH}_{3}\right)$ and nitrogen $\left(\mathrm{N}_{2}\right)$ and with the pulsed addition of carbon dioxide 
$\left(\mathrm{CO}_{2}\right)$. The total process time (heating up in a nonreactive atmosphere, nitrocarburizing, and cooling down) was $22 \mathrm{~h}$. The nitrocarburizing time was $12 \mathrm{~h}$.

After nitriding, the samples were sand blasted and polished to avoid a white layer on top of the surface. The white layer (also called the compound layer) shows low toughness, poor adhesion to PVD coatings, and a lower oxidation temperature than the PVD layer.

The PVD coating depositions were carried out in a CC 800/9ML HiPIMS system (CemeCon, Horseheads, New York). A pretreatment was carried out on the substrates before depositing the coatings. The sequence of operations and parameters used in the PVD deposition process are summarized in Table 2.

Table 2. Sequence of operations in the PVD coating deposition process and the parameters.

Sequence of Operations in the PVD Coating Deposition Process and the Parameters

Vacuum

A base pressure of $3 \mathrm{mPa}$ is achieved with the use of turbomolecular pumps and double-stage rotary paddles

Heating

Heating process with two groups of resistors at $10,000 \mathrm{~W}$ and $8000 \mathrm{~W}$.

T: $480{ }^{\circ} \mathrm{C}$. Minimum vacuum: $4 \mathrm{mPa}$

Total heating time: $1.5 \mathrm{~h}$

Ion Etching (MF-Electron Anode)

Heating: $3500 \mathrm{~W}$

Cycles of $30 \mathrm{~min}$

Bonding Layer HiPIMS

HiPIMS 1 Cr Cathode. Power: 2500-3500 W-V HiPIMS Medium frequency. Pulsed Voltage

Gas: Ar. Total pressure: $350 \mathrm{mPa}$

COATING

Phase 1 (TiAlN)

T: $480^{\circ} \mathrm{C}$. Total Pressure: $650 \mathrm{mPa}$. Gases: $\mathrm{N}_{2}$, Ar. Cathodes: Ti/Al. Power: $9.5 \mathrm{KW}$.

Cathodes: Ti/SI. Power: $0.5 \mathrm{KW}$

DC Table: 90 V, Coating Time: 2400 seg.

Phase 3 (TiAlSiN)

T: $480{ }^{\circ} \mathrm{C}$. Total pressure: $650 \mathrm{mPa}$. Gases: $\mathrm{N}_{2}$, Ar. Cathodes $\mathrm{Ti} / \mathrm{Al}$ : power ramp from $9.5 \mathrm{KW}$ to $500 \mathrm{~W}$, Cathodes Ti/Si: ramp from $0.5 \mathrm{KW}$ to $6 \mathrm{KW}$

DC: $110 \mathrm{~V}$, Coating time: $3000 \mathrm{~s}$

Cooling

$\mathrm{Up}$ to $180^{\circ} \mathrm{C}$ in a vacuum

\subsection{Thickness, Structural Properties, and Profile Composition}

The chemical composition profiles and the resultant thickness of the layers were analyzed by glow discharge optical emission spectrometry (GD-OES). The instrument employed was a JOBIN YVON 100000RF GD-OES system (HORIBA Instruments, Kyoto, Japan) [56]. To confirm the obtained results on thickness in the previous tests, a CSM Calotest instrument (CSM Instruments, Needham, MA, USA) was used. It was equipped with a $30 \mathrm{~mm}$ stainless-steel ball and a superfine $(0.25 \mu \mathrm{m})$ diamond water suspension was used as the abrasive medium.

Finally, SEM cross-section images were obtained using a HITACHI S4800 cold cathode system (HITACHI, Tokyo, Japan).

\subsection{Mechanical and Tribological Tests}

In order to obtain information about the adhesion between the substrate and the coating, adhesion tests were carried out with a CSM REVETEST Scratch tester (CSM instruments, Needham, MA, USA) equipped with a diamond Rockwell indenter with a tip radius of $200 \mu \mathrm{m}$.

In this test, the indenter moves forward at a given speed while the load is progressively increasing at a constant rate. The indenter then introduces energy into the system and, at a given load, some cracks or delamination are produced to dissipate some of the energy 
(events). The different loads at which the different modes of failure or events occur are registered with the help of various signals such as the penetration of the indenter within the substrate, the acoustic emission, and the variation in the coefficient of friction. Finally, the optical microscope allows us to obtain an image of the spot where the event occurs and helps to define the different critical loads.

The first critical load (Lc1) corresponds to the first cohesive failure observed in the coating, usually perpendicular cracks on the borders of the track; the second critical load (Lc2) is registered when the first adhesive failure is appreciated, i.e., chipping on the edges of the track; and the third critical load (Lc3) corresponds to the total delamination of the coating or when a critical defect is observed in the substrate. The second critical load (Lc2) is commonly defined as the adhesion strength due to the fact that it is considered a sign of the coating adhesion's failure [57].

The test parameters for the samples coated only with the AlTiN/TiSiN PVD layers were a load rate of $100 \mathrm{~N} / \mathrm{min}$, up to a final load of $100 \mathrm{~N}$, a speed of $9.58 \mathrm{~mm} / \mathrm{min}$, and a total test length of $10 \mathrm{~mm}$. For the duplex treatment specimens, a final load of $200 \mathrm{~N}$ and a total length of $20 \mathrm{~mm}$ were applied while keeping the same loading rate and speed.

A Microtest MT series instrument (Microtest S.A., Madrid, Spain) in a ball-on-disk configuration was used for the tribomechanical tests. For the tests, $6 \mathrm{~mm}$ alumina balls with a maximum roughness $\mathrm{Ra}_{\max }=0.050 \mu \mathrm{m}$ and hardness values of around $1650 \mathrm{HV}$ were used, and the different coated and uncoated samples were used as disks. The test parameters for the coated samples were as follows: a load of $20 \mathrm{~N}, 200 \mathrm{rpm}$, and 20,000 cycles, and the test was repeated two times for each sample at $10 \mathrm{~mm}$ and $12 \mathrm{~mm}$ track radii. For the uncoated samples, these parameters were too extreme; so, the tests were carried out at $200 \mathrm{rpm}$ for 6000 cycles and a load of $10 \mathrm{~N}$ and $5 \mathrm{~N}$ (for the $8 \mathrm{~mm}$ and $6 \mathrm{~mm}$ track radii, respectively). Confocal microscopy using a Confocal Smart microscope (Sensofar, Barcelona, Spain) and optical microscopy were used to measure the corresponding wear tracks. The volume loss and the wear coefficient were determined in two ways: straight from the confocal measurements of volume loss and according to the ASTM G99 standard [58]. This standard defines an equation that assumes that there is not significant ball wear to calculate the volume loss in the disk, and it is necessary to measure the width of the wear track. With that measurement and the information about the wear track and ball radii, the equation is applied and the value of the volume loss is obtained.

Ultra-microhardness measurements with the aim of assessing the mechanical properties were performed using a FISHERSCOPE H100 VP/X-Y micro durometer (Helmut Fischer Instruments, Sindelfingen, Germany) fitted with a Vickers diamond pyramid. Loads ranging from $200 \mu \mathrm{N}$ to $2 \mathrm{~N}$ can be applied with the indenter against the surface of the samples while the indenter position and the applied load are monitored to plot a curve that reflects the material's response to the load. In this study, two different maximum loads were used to perform the tests: $500 \mathrm{mN}$ and $1000 \mathrm{mN}$.

\section{Results}

\subsection{Thickness, Structural Properties, and Profile Composition}

GD-OES was used to analyze the chemical composition profiles and the resultant thickness of the coatings, and the results are shown in Figure 1. The sample coated only with the PVD coating showed an outermost layer of about $1 \mu \mathrm{m}$ containing (as a percentage of atomic concentration) approx. $60 \% \mathrm{~N}, 30 \% \mathrm{Ti}, 5 \% \mathrm{Si}$, and $2 \% \mathrm{Al}$. This layer is followed by another layer of around $2 \mu \mathrm{m}$ with concentrations in percentages of about $50 \% \mathrm{~N}, 30 \% \mathrm{Al}$, and $15 \%$ Ti. After these two layers, an anchoring layer-aiming to improve the adhesion to the substrate- of around $1 \mu \mathrm{m}$ of chromium can also be observed. As the PVD coating is the same in both the PVD coated sample and the duplex samples, the first two layers are identical. The main difference can be seen in the $\mathrm{N}$ percentage of the duplex samples after the first two layers as can be seen in Figure 1. While in the PVD sample the percentage of $\mathrm{N}$ decreases to nearly $0 \%$, in the duplex samples this percentage remains at $10 \%$ and $7 \%$ in 
the 1.2379 and Vanadis 4 duplex samples, respectively. This is due to the nitriding process of the duplex samples, which makes them have a thin film of iron nitride.

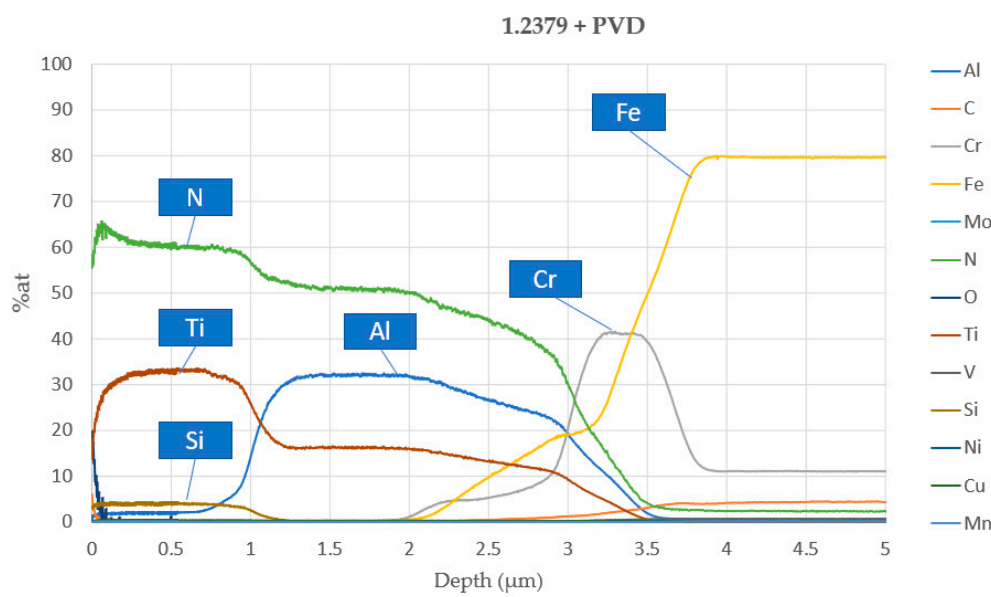

(a)

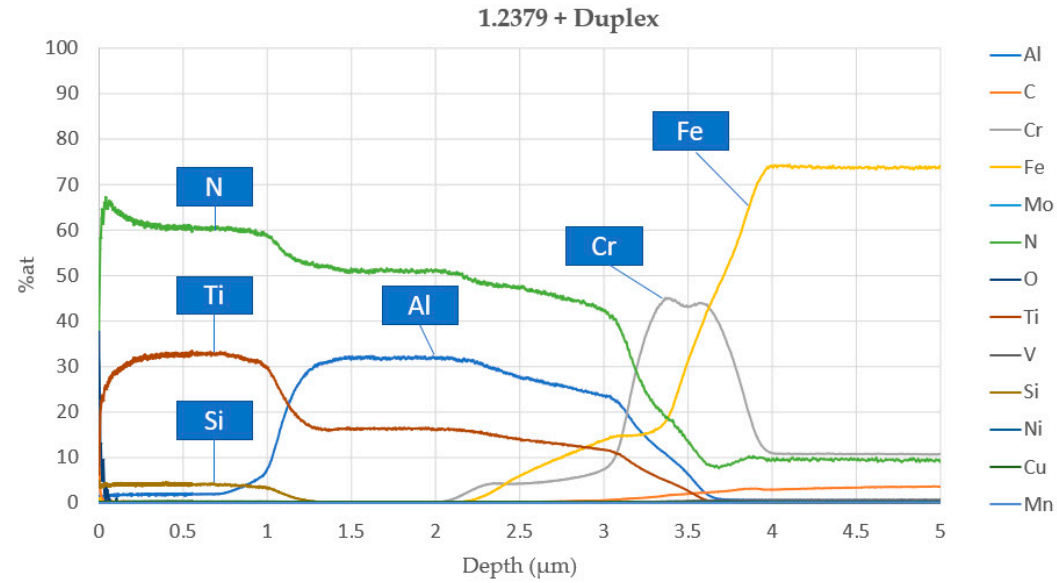

(b)

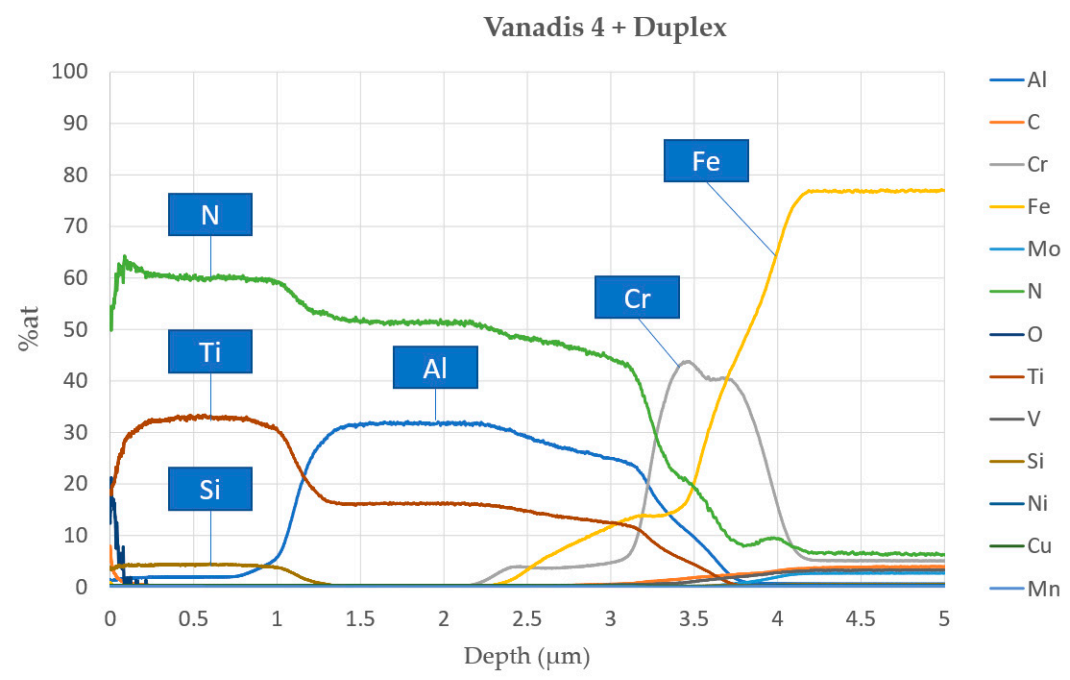

(c)

Figure 1. Glow discharge optical spectrometry (GD-OES) concentration profiles in the $1.2379+$ PVD (a), $1.2379+$ Duplex (b), and Vanadis $4+$ Duplex (c) samples. 
As has already been mentioned, this layer is meant to increase the hardness, to increase the load support effect of the substrate, and to eliminate the stress concentration at the substrate-coating interface, thus improving the adhesion between the hard coating and the substrate.

Calotest measurements that were carried out to determine the resultant thickness of the coatings showed different circumferences (Figure 2) corresponding to different depth levels that were caused by the coatings' layers with different compositions rolling the ball with the abrasives during the tests. The thickness was calculated using the relationship between these dimensions. As can be observed in Table 3, the total thickness of each coating was about $5 \mu \mathrm{m}$, with an outer layer of nearly $1.65 \mu \mathrm{m}$. A middle layer of $2.70 \mu \mathrm{m}$ was observed in the case of the 1.2379 + PVD sample, while in the duplex samples this layer is a little bit thicker $(2.90 \mu \mathrm{m})$. In the three samples, an anchoring layer of about $0.60 \mu \mathrm{m}$ can also be observed. These results are consistent with those reported in the GD-OES tests, although it is important to note that the measurements in this case are approximate, and therefore it can be observed that there are slight differences between the measured values.
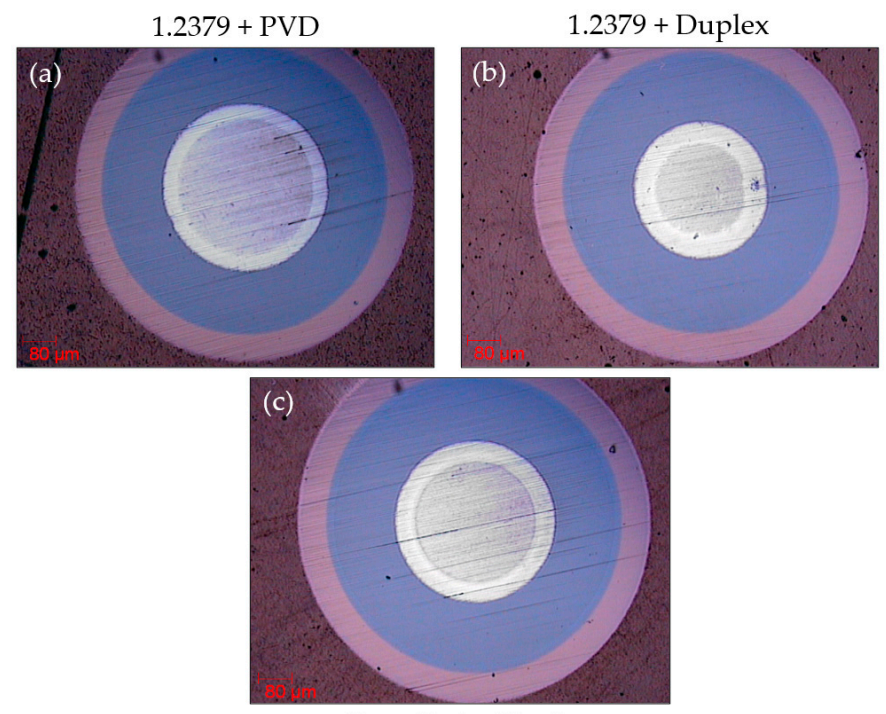

Vanadis $4+$ Duplex

Figure 2. Calotest craters used to determine the resultant thickness for the 1.2379 + PVD sample (a), 1.2379 + Duplex sample (b), and Vanadis 4 + Duplex sample (c). The different circumferences correspond to the different rings exposed after the abrasion of the coating with the balls used for the calculation of each thickness value.

Table 3. Calotest thickness measurement results obtained for each sample.

\begin{tabular}{ccccc}
\hline Sample & $\begin{array}{c}\text { Total Thickness } \\
(\boldsymbol{\mu \mathbf { m } )}\end{array}$ & $\begin{array}{c}\text { Outer Layer } \\
(\boldsymbol{\mu \mathbf { m } )}\end{array}$ & $\begin{array}{c}\text { Middle Layer } \\
(\boldsymbol{\mu} \mathbf{m})\end{array}$ & $\begin{array}{c}\text { Anchoring Layer } \\
(\boldsymbol{\mu \mathbf { m } )})\end{array}$ \\
\hline $1.2379+$ PVD & $5.01 \pm 0.03$ & $1.70 \pm 0.03$ & $2.70 \pm 0.01$ & $0.60 \pm 0.00$ \\
1.2379 + Duplex & $5.14 \pm 0.06$ & $1.65 \pm 0.07$ & $2.94 \pm 0.04$ & $0.55 \pm 0.04$ \\
Vanadis 4 + Duplex & $5.22 \pm 0.01$ & $1.65 \pm 0.01$ & $2.97 \pm 0.02$ & $0.60 \pm 0.04$ \\
\hline
\end{tabular}

Figure 3 shows the cross-section SEM pictures of the coatings, where the different layers are schematically indicated. From bottom to top:

- Anchoring layer;

- Middle layer; and

- Outer layer. 


\subsection{Ultra-Microhardness Tests}

Figure 4 illustrates an example of the ultra-microhardness load-displacement curves for the 1.2379 + PVD sample with a maximum load of $1000 \mathrm{mN}$. With these curves, it is possible to represent the material's response to the load. From these curves, it is possible to determine the Universal Hardness (HU), elastic modulus (Er), percentage of the work of elastic deformation (\% We), maximum hardness, and plastic hardness of the samples. The values of these parameters obtained for each sample and the relations between hardness and elastic modulus, $\mathrm{HU} / \mathrm{Er}$ and $\mathrm{HU}^{3} / \mathrm{Er}^{2}$, for the tests carried out with a maximum load of 500 and $1000 \mathrm{mN}$ are summarized in Tables 4 and 5, respectively. The ratio H/E represents the elastic strain to failure and $\mathrm{H}^{3} / \mathrm{E}^{2}$ the resistance to plastic deformation; thus, it is expected that an improvement in the elastic recovery of the coating would imply an increase in the $\mathrm{H}^{3} / \mathrm{E}^{2}$ ratio [59-61]. Because of this, this parameter is used to determine the toughness and the wear resistance of the coating [60,62]. Different studies have concluded that these ratios are more relevant than just the hardness to determine the wear resistance of a material and they have highlighted the influence of toughness in tribological applications. Moreover, the relation between $\mathrm{H}^{3} / \mathrm{E}^{2}$ and wear resistance has been studied, showing that the resistance to various forms of wear is related to the $\mathrm{H}^{3} / \mathrm{E}^{2}$ ratio $[59,60,62]$.
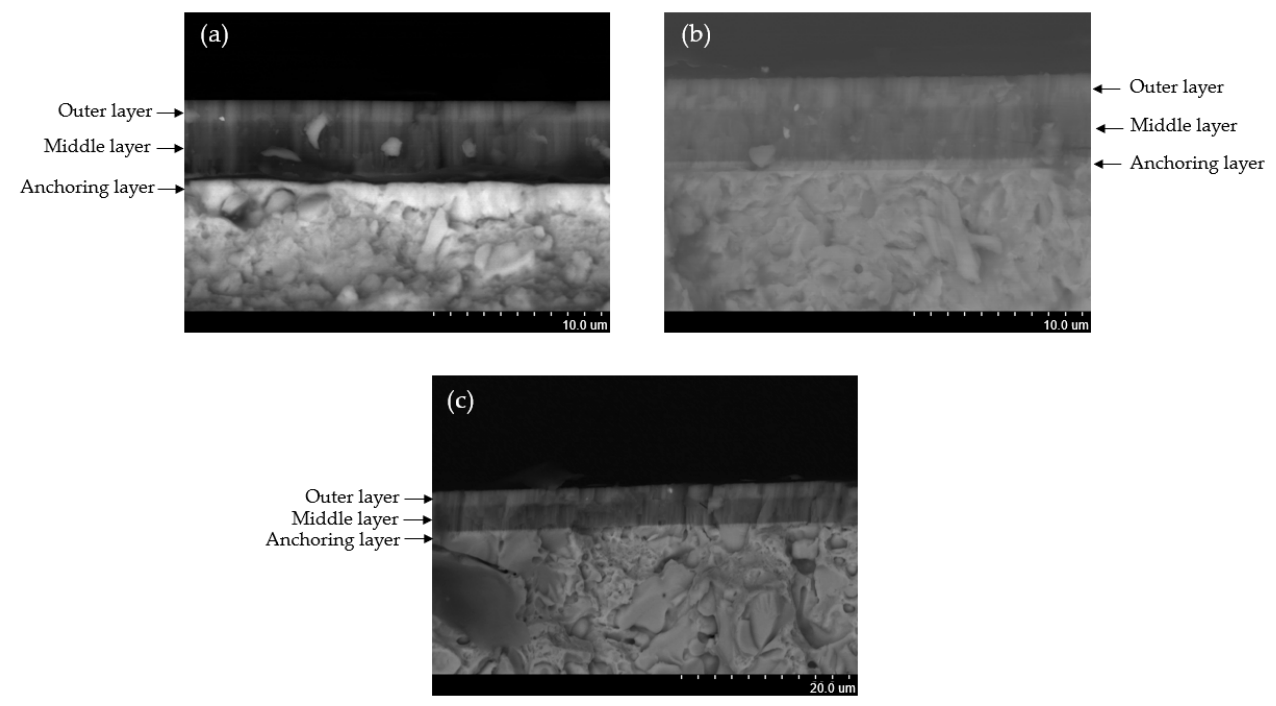

Figure 3. Cross-section SEM pictures with the coating's structure. The 1.2379 + Duplex sample (a), Vanadis 4 + Duplex sample (b) and 1.2379 + PVD sample (c).

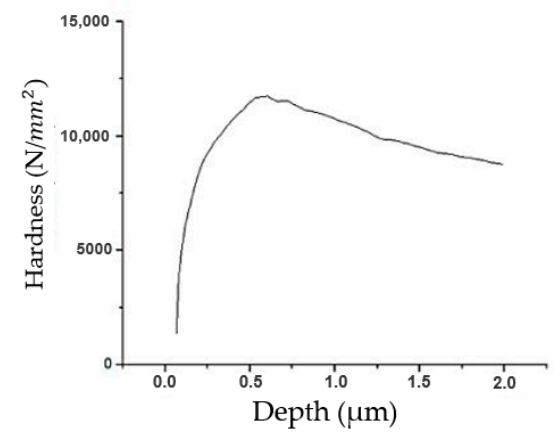

(a)

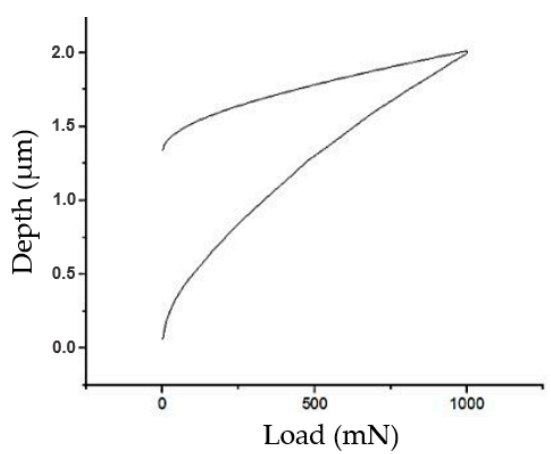

(b)

Figure 4. Example of the loading and unloading curves for the $1.2379+$ AlTiN-TiSiN sample with a maximum load of $1000 \mathrm{mN}$. The image on the left (a) represents the measured hardness value while the load increases and the indenter penetrates into the surface of the sample, thus increasing the monitored depth value. The image on the right (b) instead represents the monitoring of the indenter's position against the applied load. 
Table 4. Summary of the experimental data derived from the ultra-microhardness tests at $500 \mathrm{mN}$ : hardness (HU), elasticity (Er), elastic deformation work percentage (\% We), plastic hardness, maximum hardness, and $\mathrm{H} / \mathrm{Er}$ and $\mathrm{H}^{3} / \mathrm{Er}^{2}$ ratios.

\begin{tabular}{ccccc}
\hline Parameter & Uncoated 1.2379 & $\mathbf{1 . 2 3 7 9 + \mathbf { P V D }}$ & Duplex 1.2379 & Duplex Vanadis 4 \\
\hline $\mathrm{HU}(\mathrm{GPa})$ & $6.4 \pm 0.4$ & $9.3 \pm 0.4$ & $9.7 \pm 0.4$ & $10.3 \pm 0.3$ \\
$\mathrm{Er}(\mathrm{Gpa})$ & $235 \pm 3$ & $299 \pm 3$ & $306 \pm 4$ & $328 \pm 4$ \\
\% We & $31 \%$ & $37 \%$ & $39 \%$ & $40 \%$ \\
Plastic Hardness (GPa) & $9.8 \pm 0.1$ & $16.3 \pm 0.1$ & $17.4 \pm 0.1$ & $18.8 \pm 0.1$ \\
Maximum hardness (GPa) & $6.4 \pm 0.3$ & $11.1 \pm 0.4$ & $11.2 \pm 0.6$ & $11.6 \pm 0.7$ \\
$\mathrm{HU} / \mathrm{Er}$ & 0.0272 & 0.0309 & 0.0313 & 0.0314 \\
$\mathrm{HU}^{3} / \mathrm{Er}^{2}(\mathrm{GPa})$ & 0.0047 & 0.0088 & 0.0095 & 0.0102 \\
\hline
\end{tabular}

Table 5. Summary of the experimental data derived from the ultra-microhardness tests at $1000 \mathrm{mN}$ : hardness (HU), elasticity (Er), elastic deformation work percentage (\% We), plastic hardness, maximum hardness, and $\mathrm{H} / \mathrm{Er}$ and $\mathrm{H}^{3} / \mathrm{Er}^{2}$ ratios.

\begin{tabular}{ccccc}
\hline Parameter & Uncoated 1.2379 & $\mathbf{1 . 2 3 7 9 + \mathbf { P V D }}$ & Duplex 1.2379 & Duplex Vanadis 4 \\
\hline $\mathrm{HU}(\mathrm{GPa})$ & $6.5 \pm 0.7$ & $8.5 \pm 0.4$ & $8.9 \pm 0.7$ & $9.7 \pm 0.2$ \\
Er $(\mathrm{Gpa})$ & $248 \pm 1$ & $298 \pm 1$ & $308 \pm 2$ & $329 \pm 1$ \\
\% We & $31 \%$ & $34 \%$ & $35 \%$ & $37 \%$ \\
Plastic Hardness (GPa) & $9.9 \pm 0.1$ & $13.9 \pm 0.1$ & $14.8 \pm 0.1$ & $16.7 \pm 0.1$ \\
Maximum hardness (GPa) & $6.8 \pm 0.6$ & $11.2 \pm 0.4$ & $11.2 \pm 0.6$ & $11.8 \pm 0.6$ \\
HU/Er & 0.0264 & 0.0285 & 0.0289 & 0.0295 \\
$\mathrm{HU}^{3} / \mathrm{Er}^{2}(\mathrm{GPa})$ & 0.0046 & 0.0069 & 0.0074 & 0.0084 \\
\hline
\end{tabular}

Observing the results summarized in Tables 4 and 5, it can be seen how the Universal Hardness (HU) and the elastic modulus (Er) are higher in the coated samples; the highest values were obtained for the duplex coated Vanadis 4 sample. Despite the differences, the values obtained are similar for both duplex coated samples, with HU values of around 9-10 GPa. The elastic modulus, however, is more similar in the case of 1.2379 specimens coated with PVD and duplex treatments, with values of approximately $300 \mathrm{GPa}$, than in the case of the specimen with Vanadis 4 as a substrate, which showed values of 328-329 GPa. The elastic deformation work percentage (\% We) and the ratios between hardness and elastic modulus ( $\mathrm{HU} / \mathrm{Er}$ and $\mathrm{HU}^{3} / \mathrm{Er}^{2}$ ) are similar in all of the coated samples, showing greater values than those obtained for the uncoated 1.2379 specimen. If we go into detail, it can be said that the duplex samples showed the highest $\mathrm{HU} / \mathrm{Er}$ and $\mathrm{HU}^{3} / \mathrm{Er}^{2}$ values, and the greatest resistance to plastic deformation was obtained in the case of the Vanadis 4 + Duplex sample.

\subsection{Adhesion Tests}

The adhesion between the coatings and the substrates and their mechanical response were evaluated by scratch testing. The results obtained for each sample are shown in Figure 5. The failure modes along the scratches were observed and the critical loads (Lc1, Lc2, and Lc3) where these failures occurred were spotted through the sudden changes in the evolution of the COF and sharp rises in the AE signal. Pictures of the different spots where the different features are related to either Lc1, Lc2, or Lc3 are also shown in Figure 5.

As was mentioned above, each critical load represents a different failure mechanism (cohesive (Lc1), adhesive (Lc2), or the appearance of the substrate (Lc3)) and with their values it is possible to evaluate the differences in the adhesion properties of the samples. Apart from the adhesion properties, the value of Lc1 and the difference between Lc2 and Lc1 (Lc2-Lc1) can provide information about the toughness of the coating. Zhang et al. [63] proposed a new parameter to evaluate the toughness of the coating: the scratch crack propagation resistance (CPR) as shown in Formula (1). Higher CPR values are related to a greater capacity of the coating to resist crack propagations [64].

$$
\mathrm{CPRs}=\mathrm{Lc} 1 \cdot(\mathrm{Lc} 2-\mathrm{Lc} 1)
$$



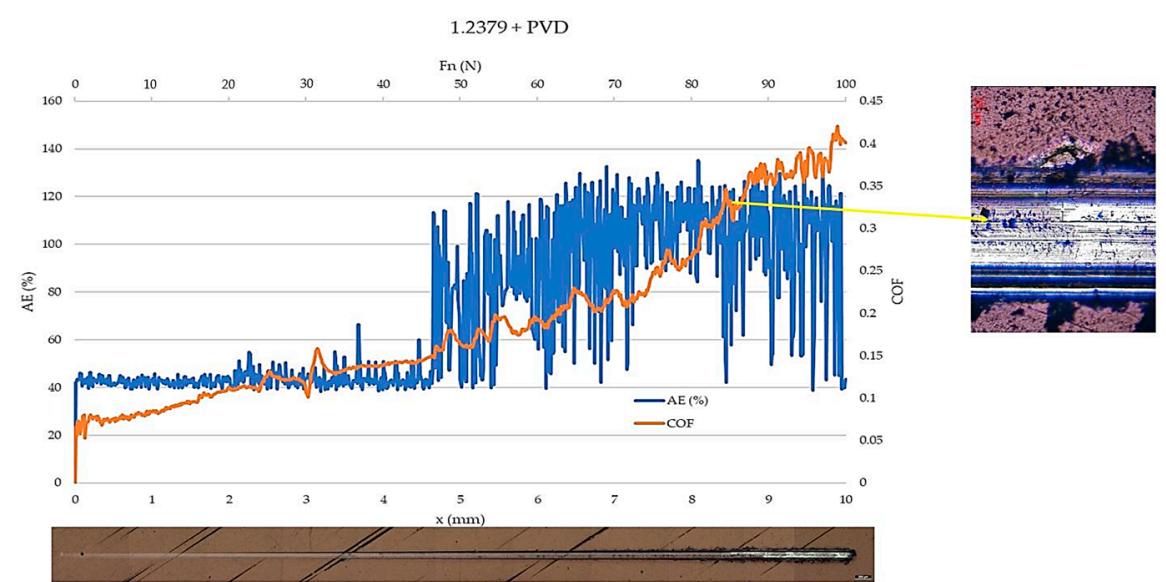

(a)
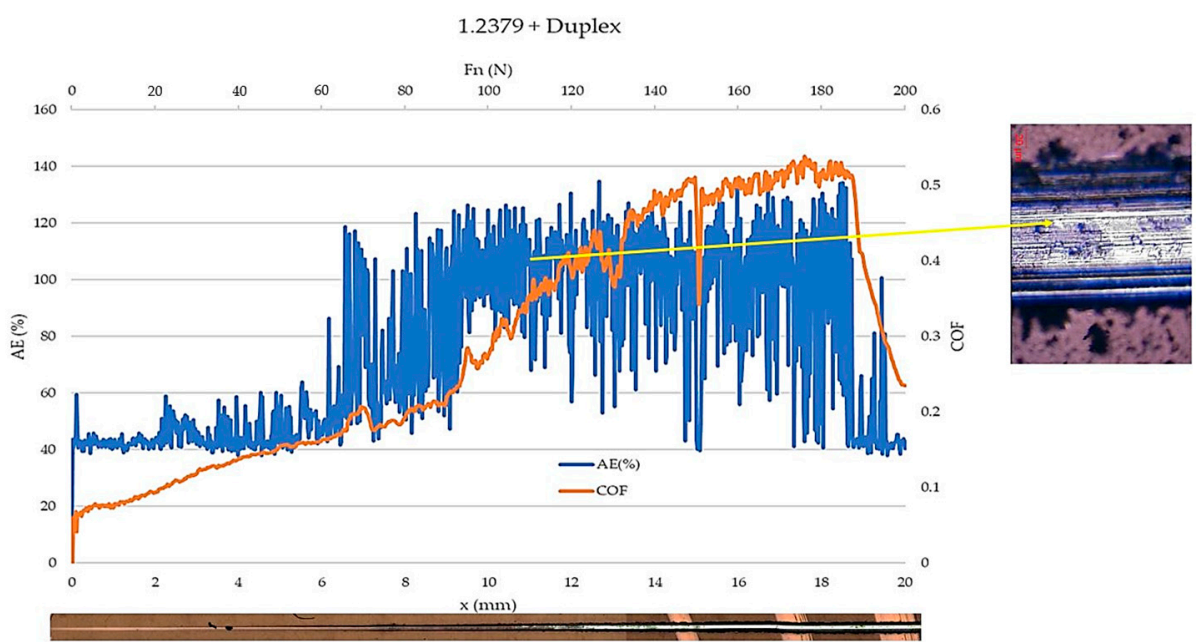

(b)

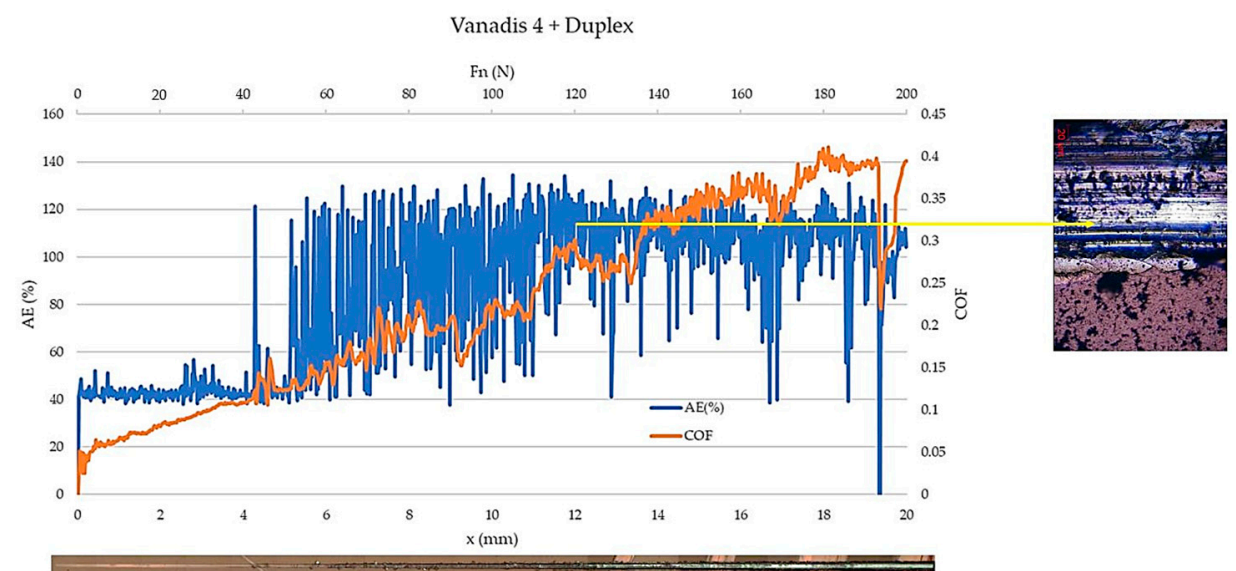

(c)

Figure 5. Scratch test results. Evolution of the coefficient of friction (orange plot) and acoustic emission (blue plot) vs. the indenter displacement and the normal force: 1.2379 + PVD sample (a), $1.2379+$ Duplex sample (b), and Vanadis $4+$ Duplex sample (c).

Table 6 summarizes the results of the critical loads for each sample. The results show very promising values since high critical values were reached, especially for duplextreated specimens. As can be observed, the samples coated with duplex presented higher critical load values (Lc1, Lc2, and Lc3) than the sample coated only with PVD in all cases. Furthermore, although the two duplex-coated samples presented similar Lc2 and Lc3 
values, it should be noted that the best results were obtained in both cases for the Vanadis 4 sample. The adhesion values obtained in this study are higher than those reported in other studies where conventional PVD techniques were used. References $[65,66]$ reported Lc2 values of around 80-90 N for high-speed steel substrates coated by cathodic arc evaporation PVD (AlTiN and AlCrN, respectively), while [67] presented Lc2 values of $30 \mathrm{~N}$ for multilayer Ti/TiAlN/TiAlCN coatings deposited on tool steels by magnetron sputtering. Many other studies showed Lc2 values from $50 \mathrm{~N}$ to $80 \mathrm{~N}$ for duplex (nitriding + PVD) hard coatings deposited on tool steels [1,68-70]. Furthermore, the values obtained in this study are similar, and even higher in some cases, to those reported for novel PVD techniques such as hybrid PVD [25,71] and closed-field unbalanced magnetron sputtering ion plating (CFUMSIP) [53,61], which presented adhesion strength values up to $116 \mathrm{~N}$ and $143 \mathrm{~N}$, respectively. These values can even be compared with those obtained in studies using carbides as substrates, such as [22,23], that showed Lc2 values of approximately $100 \mathrm{~N}$. Finally, it can be said that these results show how this duplex treatment improves the adhesion properties of the conventional PVD magnetron sputtering techniques, making them capable of competing with other types of techniques that to date they have not been able to compete with.

Table 6. Summary of the critical load values obtained for each sample from the scratch test.

\begin{tabular}{cccc}
\hline Sample & Lc1 (N) & Lc2 (N) & Lc3 (N) \\
\hline 1.2379 + PVD & 46 & 75 & 85 \\
Duplex 1.2379 & 62 & 96 & 109 \\
Duplex Vanadis 4 & 48 & 109 & 116 \\
\hline
\end{tabular}

The values of the first critical load (Lc1), the adhesion strength (Lc2), and the CPR of each sample are presented in Figure 6. As can be seen, the toughness of the coatings, represented by the CPR value, is much higher in the case of the duplex samples. The 1.2379 + PVD specimen presented a value of $1334 \mathrm{~N}^{2}$, while the sample with the same substrate but coated with the duplex treatment showed a CPR value of $2108 \mathrm{~N}^{2}$. Furthermore, the toughness of the duplex-treated Vanadis 4 sample was even greater than the 1.2379 duplex's, with a CPR value of $2928 \mathrm{~N}^{2}$. These values indicate the great capacity of the coatings to resist crack propagation, and are higher than those reported in [53], which reported CPR values of approximately $1468 \mathrm{~N}^{2}$ for $\mathrm{NiCrN}$ coatings deposited on M2 tool steel, and in [66], which showed CPR values of around $1900 \mathrm{~N}^{2}$ for AlCrN coatings deposited on HS6-5-2 steel. However, similar results were reported in [61], with CPR values between 1500 and $4300 \mathrm{~N}^{2}$ depending on the Ni content of the CrAlNiN coatings deposited onto AISI M2 high-speed tool steel substrates. The CPR values, which are related to the toughness of the coating, present a similar trend to the values obtained for the relation between $\mathrm{HU}^{3}$ and $\mathrm{Er}^{2}$, which is also related to the toughness. The comparison of the trends of the values obtained for these two parameters is shown in Figure 7 where it can be seen how the highest values in both cases were obtained for the Vanadis 4 + duplex sample.

\subsection{Friction and Wear Tests}

The friction and wear properties of the coatings as well as those of the reference substrate were studied by a pin-on-disc tribometer. The experimental results on the coefficients of friction (COFs) are shown in Figure 8. COF values of around 0.65 were shown by all specimens. The fluctuations in the COF curves are inherent to the test itself during the run-in period, while, during steady state, the appearance of different tribooxidation bodies is the cause of this phenomenon. The fact that all the samples have nearly the same slightly high COF value can be explained because the coating used in this study is not a low-COF coating but rather a hard coating, and the top layer is the same for all the samples. However, as will be seen later, these coatings improve the wear resistance of the uncoated samples. The COF values are similar to those reported by Warcholinski et al. [66], where $\mathrm{COF}$ values between 0.62 and 0.68 were reported for $\mathrm{AlCrN}$ coatings deposited 
using Cathodic Arc Evaporation on HS6-5-2 steel substrates, and in [49], where values of around $0.5-0.75$ were reported for duplex PVD nanocomposite TiAlN coatings deposited on different steels. References $[67,68]$, however, showed lower COF values, around 0.3-0.4, for Ti/TiAlN/TiAlCN multilayer coatings and graded TiAlN coatings deposited on tool steels, respectively.

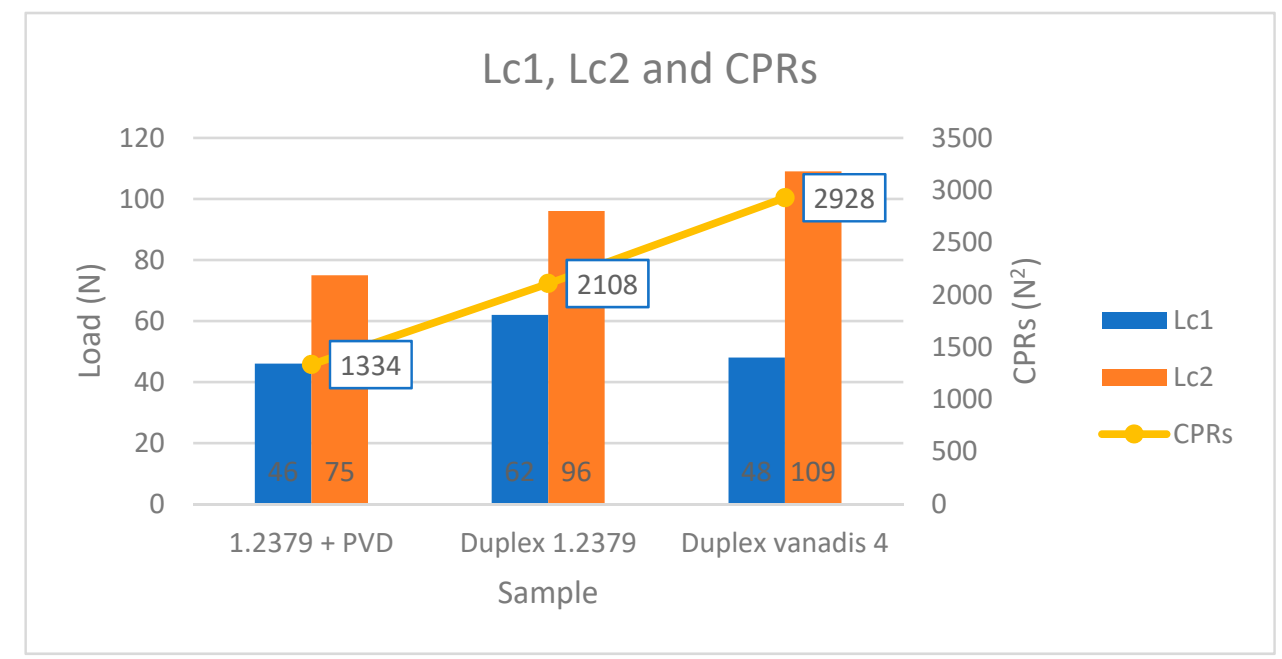

Figure 6. Lc1, Lc2, and CPR values for each coated sample (1.2379 + PVD, Duplex + 1.2379, and Duplex + Vanadis 4).

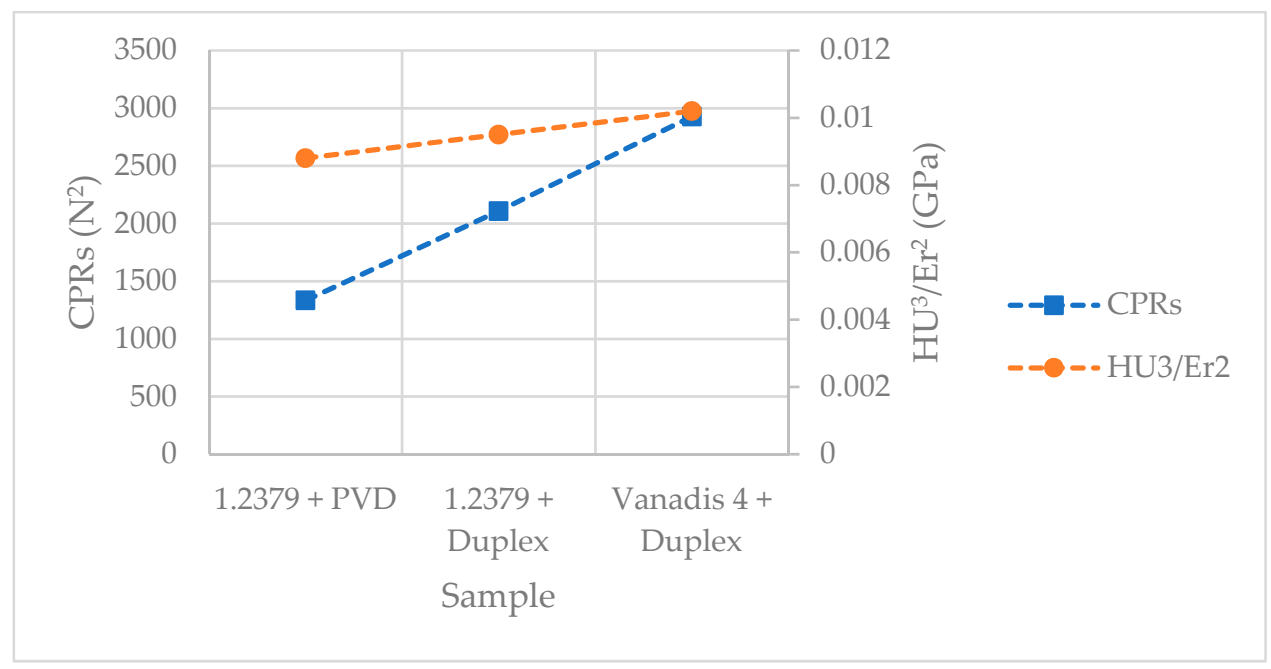

Figure 7. $\mathrm{CPR}$ and $\mathrm{HU}^{3} / \mathrm{Er}^{2}$ values for each coated sample $(1.2379+\mathrm{PVD}$, Duplex +1.2379 , and Duplex + Vanadis 4).

The width of the wear tracks obtained by optical microscopy and confocal microscopy is shown in Figure 9, where the differences are evident. The width of the wear tracks is between 560 and $906 \mu \mathrm{m}$ for the uncoated sample, but it must be remembered that the tests on this sample were carried out under less-demanding conditions. The PVD-coated sample, instead, presents values of around 1156-1564 $\mu \mathrm{m}$, while the duplex-coated samples are approximately $840-1120 \mu \mathrm{m}$. As expected, the coated samples improved the wear resistance of the substrate, and the duplex samples showed lower values of the width of the wear track than the PVD-coated sample. Moreover, the wear mechanisms present in each coated sample were very similar. Observing the images shown in Figure 9, the three coated samples show very little abrasive wear, with few microscratches, while the non-nitrided PVD-coated sample shows a little bit more abrasive wear, which is an indicator of good wear resistance. 


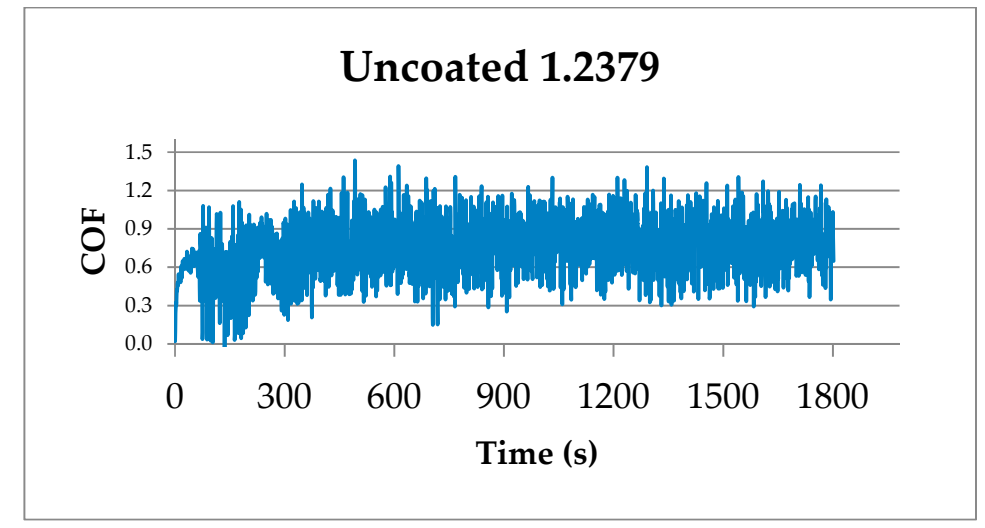

(a)

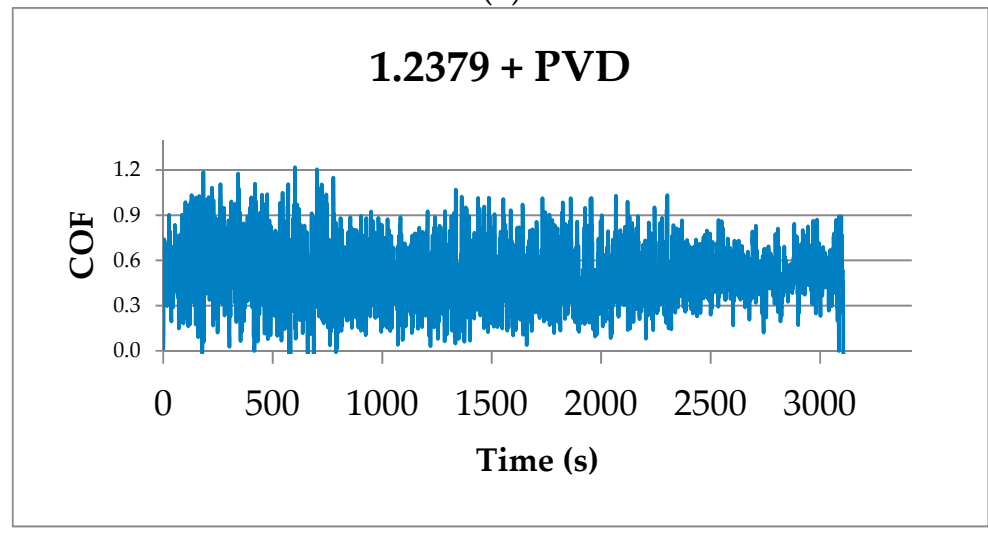

(b)

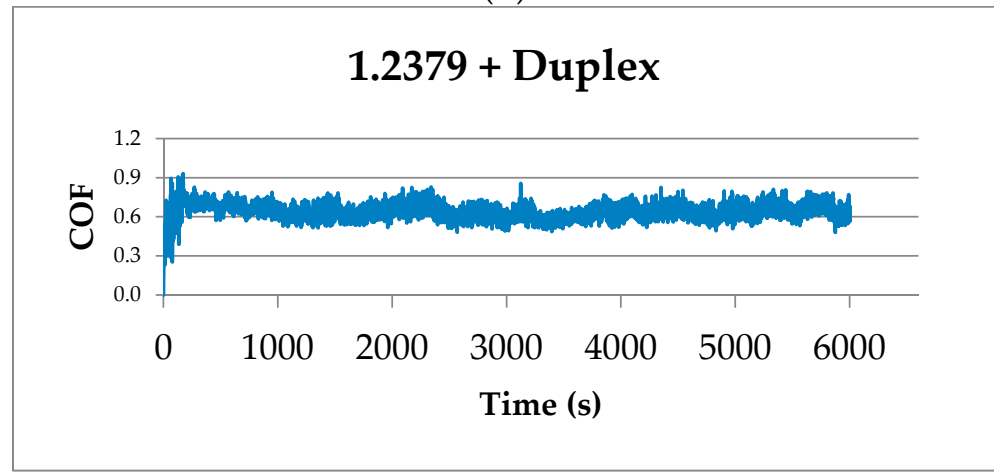

(c)

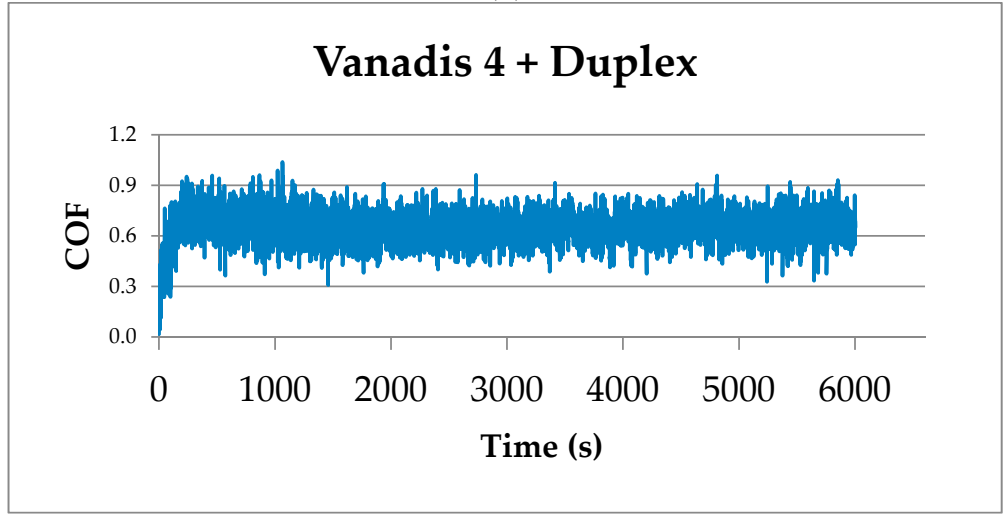

(d)

Figure 8. Friction coefficient (COF) test results for the uncoated 1.2379 sample (a), $1.2379+$ PVD sample (b), 1.2379 + Duplex sample (c), and Vanadis 4 + Duplex sample (d). 


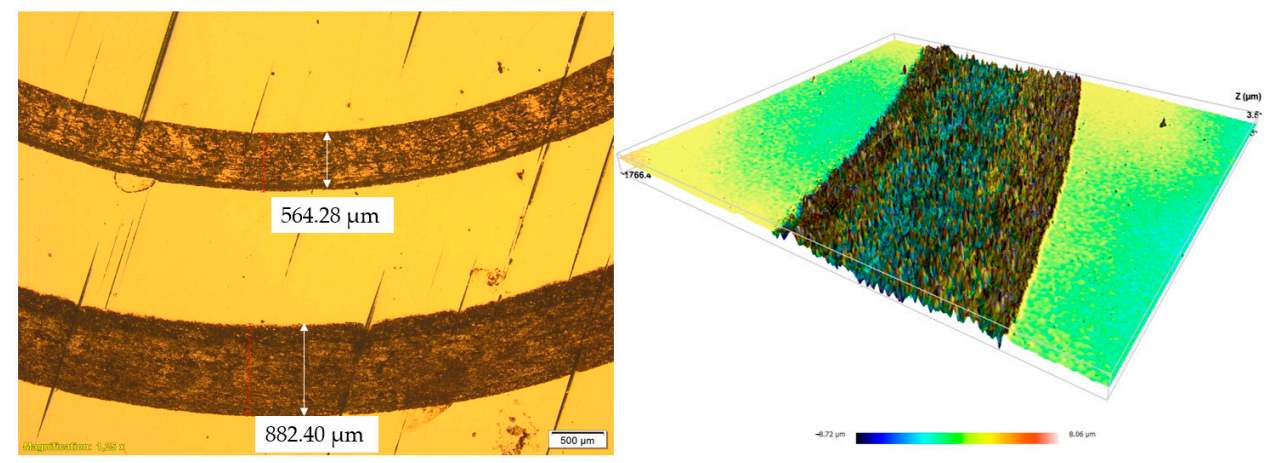

(a)
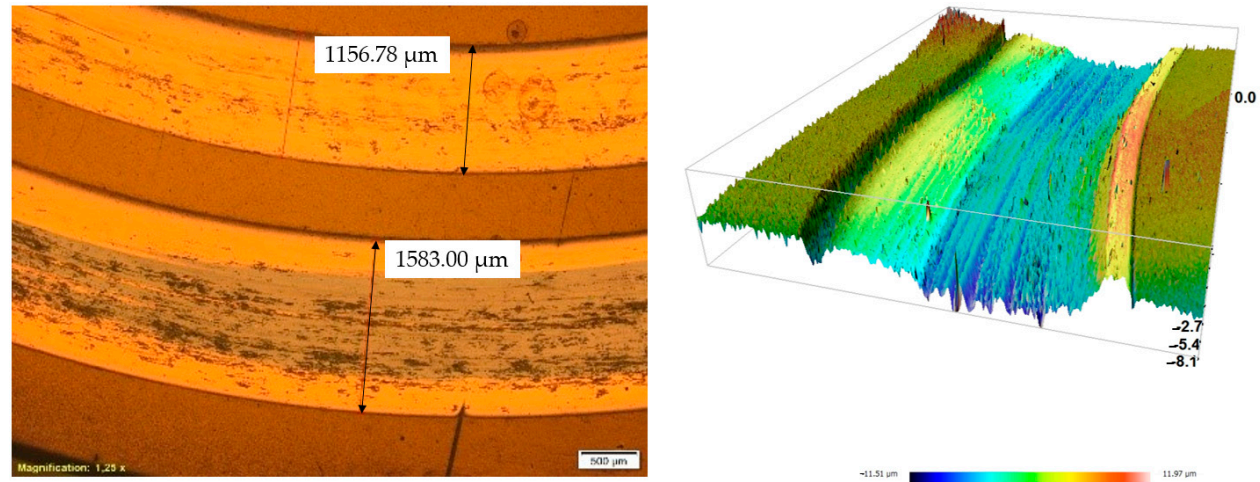

(b)
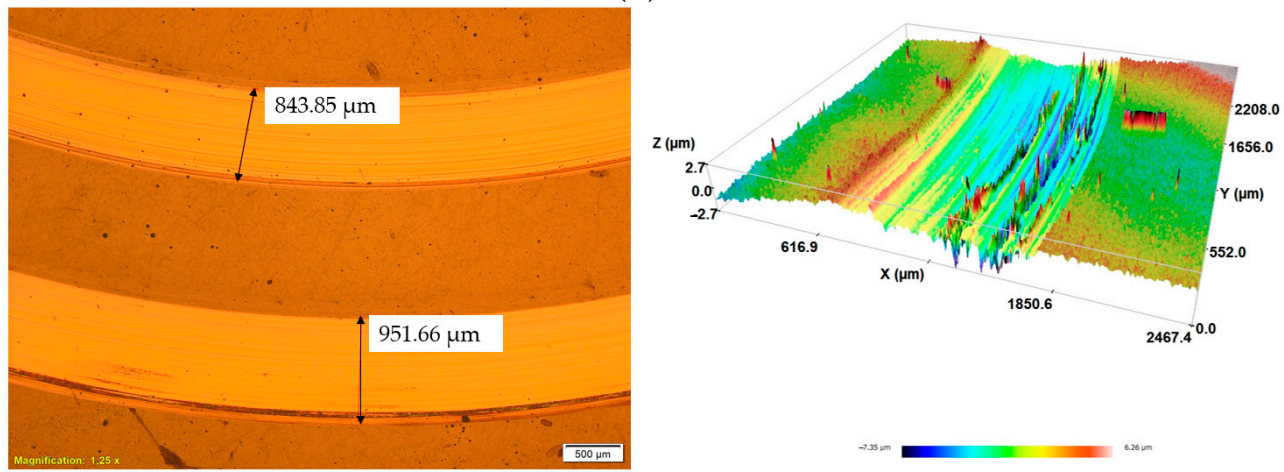

(c)
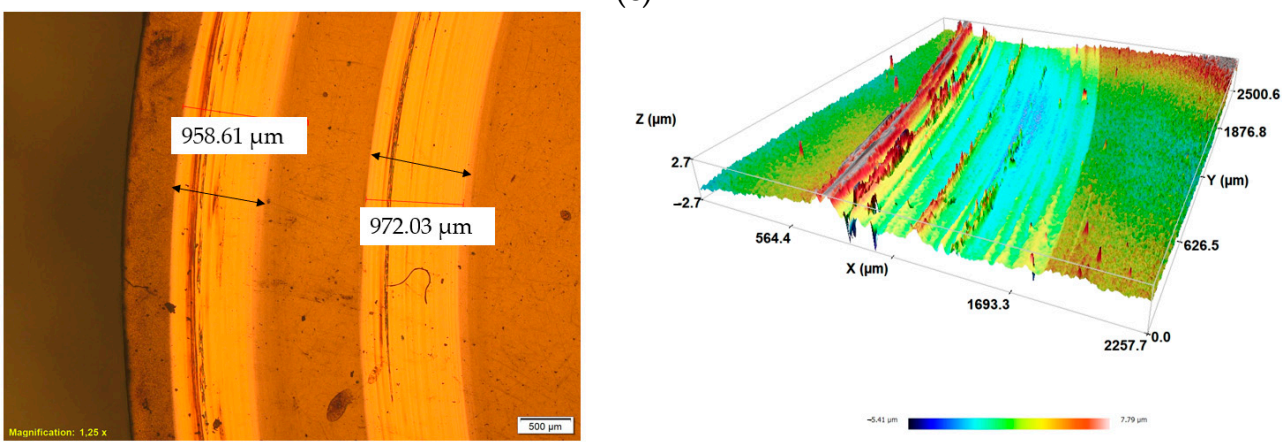

(d)

Figure 9. Example of the wear tracks obtained by optical microscopy (left) and confocal microscopy (right) for the uncoated 1.2379 sample (a), 1.2379 + PVD sample (b), 1.2379 + Duplex sample (c), and Vanadis 4 + Duplex sample (d).

The volume loss and the wear coefficient were evaluated using two different methods: the standard ASTM G99 and directly using the results obtained by confocal microscopy. For the first method, the width of the wear track was measured by optical microscopy, and 
then we followed the standard ASTM G99 to determine the value of the volume loss for the entire track. Afterward, the calculated value was used to determine the wear coefficient through a formula that relates it to the applied load in the test and the total sliding distance, thus obtaining a normalized value. In the second method, the volume loss of the focused part of the wear track is calculated directly using a confocal microscope and the Sensoview program, and then that value is extrapolated for the entire wear track using the equation shown in Formula (2). Then, the same equation used in the first method is used to calculate the wear coefficient.

$$
\frac{V \text { loss confocal }\left(\mathrm{m}^{3}\right)}{\text { wear track length }(\mathrm{m})} \times 2 \times \Pi \times \mathrm{r}(\mathrm{m})=\mathrm{V} \text { loss }\left(\mathrm{m}^{3}\right)
$$

Table 7 and Figures 10 and 11 show a summary of the results on the friction coefficient, volume loss, and wear coefficient calculated with both the standard ASTM G99 and confocal microscopy. The values shown are the average values of the results obtained for the tests that were carried out with different track radii. A difference of approximately an order of magnitude can be observed between the values by both methods. In the calculations carried out following the standard ASTM G99, it was assumed that the shape of the wear track is that of a perfect sphere, while by confocal microscopy the real shape of the wear track was used for calculating the volume loss. Anyway, both methods show the same trend, and the wear coefficient is lower for the duplex-coated samples in both cases, which indicates a better wear resistance. Values of $(2.49 \pm 1.11) \times 10^{-4}$ and $(1.30 \pm 0.18) \times 10^{-5} \mathrm{~mm}^{3} / \mathrm{Nm}$ were obtained for the uncoated samples using the ASTM G99 and the confocal measurements, respectively. For the 1.2379 + PVD sample, nonetheless, the values were lower: $(2.23 \pm 0.133) \times 10^{-4} \mathrm{~mm}^{3} / \mathrm{Nm}$ for the ASTM G99 measurements and $(4.10 \pm 0.63) \times 10^{-6} \mathrm{~mm}^{3} / \mathrm{Nm}$ for the confocal ones. As mentioned above, the lowest wear coefficient values were presented by the duplex samples, with values of around $6.35 \times 10^{-5} \mathrm{~mm}^{3} / \mathrm{Nm}$ in the ASTM G99 results and between $1.75 \times 10^{-6}$ and $1.96 \times 10^{-6} \mathrm{~mm}^{3} / \mathrm{Nm}$ in the confocal measurements. As expected, the duplex treatment improved both the adhesion of the coatings and their wear resistance. Different studies showed that the nitrides and carbonitrides formed during the nitriding process contribute to the improvement of the wear resistance [72,73]. These wear coefficient results are similar to those reported in reference [53], ranging between $0.23 \times 10^{-6}$ and $9.5 \times 10^{-6} \mathrm{~mm}^{3} / \mathrm{Nm}$ for $\mathrm{NiCrN}$ coatings deposited on M2 tool steel, reference [67], showing values of $3.7624 \times 10^{-15} \mathrm{~m}^{3} / \mathrm{Nm}$, and reference [49], with values of around $12 \times 10^{-16}$ $400 \times 10^{-16} \mathrm{~m}^{3} / \mathrm{Nm}$. On the other hand, lower wear coefficient values were reported in $[66,74]$, with wear coefficient values of around $2.5 \times 10^{-7} \mathrm{~m}^{3} / \mathrm{Nm}$ for $\mathrm{Cr} / \mathrm{CrN} / \mathrm{CrTiN}$ and $\mathrm{AlCrN}$ coatings deposited on tool steels, respectively.

Figures 10 and 11 present the wear coefficient values for each sample calculated by both methods (ASTM G99 (Figure 10) and confocal microscopy (Figure 11)). As can be seen, they show good repeatability in the tribological test. Additionally, a difference of about an order of magnitude between the results obtained by the different methods is evident in these graphs.

Table 7. Summary of the experimental data on the friction coefficient and volume loss measured by ASTM G99 and confocal microscopy for each sample. * The test parameters for the uncoated sample were different to those for the rest.

\begin{tabular}{cccc}
\hline Sample & Friction Coefficient & $\begin{array}{c}\text { Volume Loss } \mathbf{( m}^{\mathbf{3}} \text { ) } \\
\text { ASTM G99 }\end{array}$ & $\begin{array}{c}\left.\text { Volume Loss } \mathbf{( m}^{\mathbf{3}}\right) \\
\text { Confocal }\end{array}$ \\
\hline Uncoated 1.2379* & 0.65 & $(5.90 \pm 4.36) \times 10^{-10}$ & $(2.81 \pm 1.74) \times 10^{-11}$ \\
$1.2379+$ PVD & 0.645 & $(5.03 \pm 2.94) \times 10^{-9}$ & $(5.49 \pm 0.52) \times 10^{-10}$ \\
Duplex + 1.2379 & 0.65 & $(1.86 \pm 0.97) \times 10^{-9}$ & $(4.88 \pm 1.67) \times 10^{-11}$ \\
Duplex + Vanadis 4 & 0.69 & $(1.81 \pm 0.66) \times 10^{-9}$ & $(5.27 \pm 3.00) \times 10^{-11}$ \\
\hline
\end{tabular}




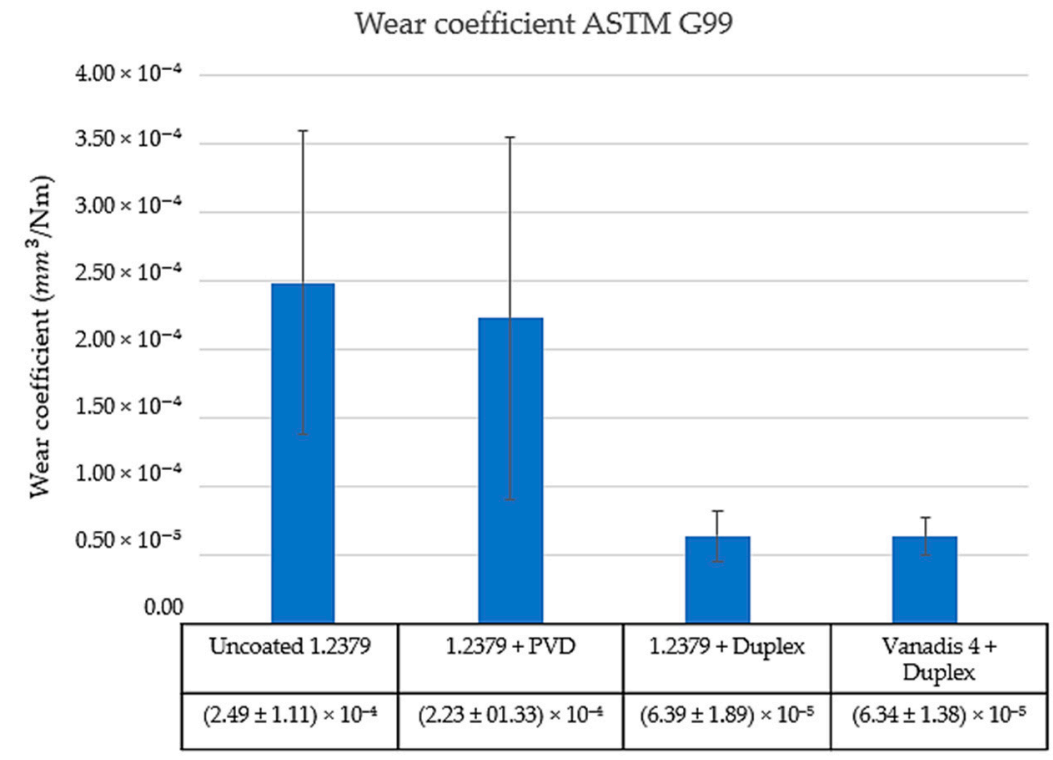

Figure 10. Comparative graph of the wear coefficient values calculated by ASTM G99 for each sample.

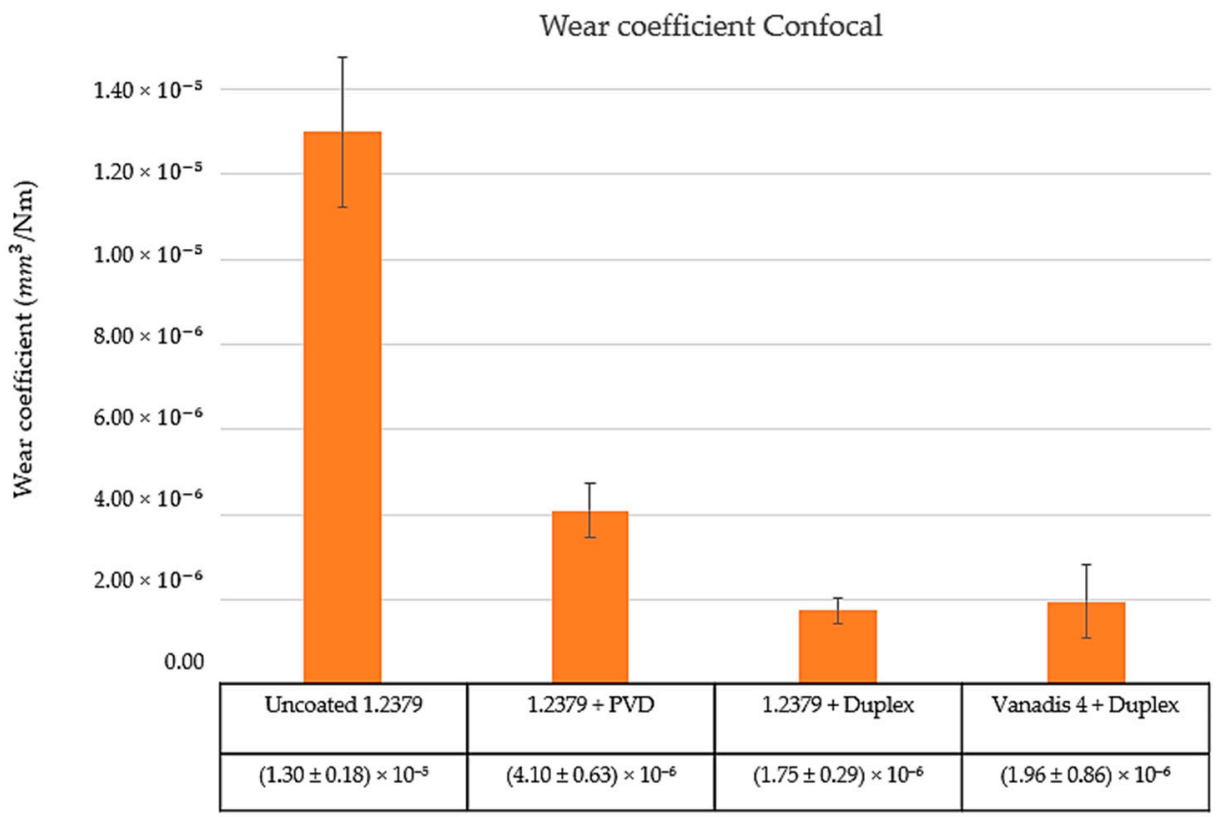

Figure 11. Comparative graph of the wear coefficient values calculated by confocal microscopy for each sample.

\section{Discussion}

Once all the tests have been carried out on all the samples, it is possible to comment on and relate some of the results to discuss the properties of the different coatings. First of all, GD-OES spectrometry showed the chemical composition profiles and the resultant thickness of the coatings, where it was possible to observe that the duplex coatings had higher nitrogen content due to the nitriding process. The compressive stresses formed in the nitrided region increase the load bearing capacity, plastic deformation, and the adhesion of the PVD coatings. The PVD coating, meanwhile, improved the hardness and tribological properties of the substrates. Related to this, the differences observed in the ultra-microhardness results were very small, since the top layer is the same in all the coated specimens. Thus, values of around 8.5-10 GPa were obtained for all the coated specimens.

It should also be noted that in this study the toughness of the coatings was estimated by two different parameters: the relation between hardness and elastic modulus $\left(\mathrm{HU}^{3} / \mathrm{Er}^{2}\right)$, 
which is related to the resistance to plastic deformation, and the CPR value, which is considered to represent the scratch crack propagation resistance by some authors. Higher $\mathrm{H}^{3} / \mathrm{E}^{2}$ and CPR values suppose a greater capacity of the coatings to resist plastic deformation and crack propagation, respectively. As shown in Figure 8, the duplex-treated samples showed higher values than the non-nitrided sample for both parameters. The CPR results are especially good, with values up to $2928 \mathrm{~N}^{2}$ for the Vanadis 4 duplex-treated sample. On the other hand, as already mentioned, the toughness of the coating has an influence on the tribological properties, so that a greater toughness indicates a greater wear resistance. This correlation can clearly be seen in this study, since the duplex-treated samples showed higher toughness and greater wear resistance than the non-nitrided samples.

The slight discrepancies of approximately an order of magnitude that were observed in the wear coefficient measurements with both different methods-following the ASTM G99 standard and from the confocal microscope directly-may be associated with the shape of the wear tracks. During the pin-on-disc tests, the alumina balls suffer a small amount of wear, so they do not have a perfect spherical shape; therefore, the shape of the wear tracks is not that of a perfect sphere either. The ASTM G99 standard defines the calculations of the volume loss taking the shape of the wear track as that caused by a perfect sphere, while the measurements made by confocal microscopy consider its real shape. This could be the reason why the values obtained by confocal measurements are lower but more realistic.

The objective of this study was focused on improving the adhesion properties of the coatings and, as seen in the results, nitriding the samples led to a clear improvement in their adhesion strength. This is demonstrated by the critical load (Lc1, Lc2, and Lc3) results obtained for each sample, where the duplex samples showed higher values than the non-nitrided samples for all samples. The PVD-coated 1.2379 sample showed values of 46 $\mathrm{N}, 75 \mathrm{~N}$, and $85 \mathrm{~N}$ for Lc1, Lc2, and Lc3, respectively, whereas the duplex-treated 1.2379 sample showed values of $62 \mathrm{~N}, 96 \mathrm{~N}$, and $109 \mathrm{~N}$. The Vanadis 4 duplex-treated sample showed values even greater than those of the 1.2379 one, with values of $109 \mathrm{~N}$ for Lc2 and $116 \mathrm{~N}$ for Lc3.

Comparing the results of this study with those observed in other studies, it can be seen that the critical load values obtained in the scratch tests are higher than those reported in studies that used cathodic arc techniques [65,66] or duplex treatments [68-70]. Furthermore, the adhesion properties observed in this work are even higher than those reported in studies that use novel PVD techniques such as hybrid PVD or closed field unbalanced magnetron sputtering ion plating (CFUMSIP) [25,61,71]. Thereby, it is possible to highlight the improvement in adhesion achieved in this study. As mentioned above, the duplex treatment also improves other properties, such as wear resistance and toughness. The values obtained in the wear tests are similar to those reported in other studies that evaluated the performance of hard coatings deposited on tool steels $[49,53,67]$, and the CPR values, which are related to the toughness of the coating, are similar and even higher than those reported in references $[53,61,66]$.

In summary, combining the nitriding process with the AlTiN-TiSiN coating deposited by HiPIMS and DCMS does not improve only the adhesion between the coating and the substrate, but it also leads to an improvement in other properties, such as toughness and wear resistance. This combination of the nitriding process and the AlTiN-TiSiN coating formed by first depositing a bonding layer by HiPIMS and then other layers by DCMS optimizes the deposition process, achieving coatings with greater properties. The nitrided layer can improve the adhesion and the load bearing capacity of the coatings, whereas the highly ionized plasma of the HiPIMS process allows us to have a higher ion bombardment of the growing film, which translates to denser coatings with improved mechanical properties, providing them with better adhesion to the substrate.

Finally, it should be noted that small differences between the substrates were observed. Comparing the results obtained for the duplex-coated Vanadis 4, which is a powder metallurgical steel, and for the duplex-coated 1.2379, which is a conventional steel, it can be seen that the value of the adhesion strength (Lc2) is higher in the case of the 
Vanadis 4 sample. Furthermore, the toughness of the coating is also greater for this sample, both for the $\mathrm{HU}^{3} / \mathrm{Er}^{2}$ value and for the CPR value. The higher quality of the powder metallurgical steels, where a better dimensional stability, a greater homogeneity of the carbides, and greater mechanical properties can be highlighted, could be the reason for this better behavior. Although it would be necessary to carry out more studies to provide the reason for this better behavior, there are some aspects that could explain it. First of all, a lower strain on the interface between the substrate and the coating due to a more homogeneous distribution of the residual stresses could lead to a greater capacity to withstand the loads transmitted through the coating. On the other hand, the higher vanadium content in powder metallurgical steels could be a reason for their greater yield strength than conventional steel, which allows them to have a better behavior under load.

\section{Conclusions}

In this study, nitrided high-quality tool steels were coated with AlTiN-TiSiN coatings deposited by a combination of HiPIMS and DCMS. The aim of this study was to improve the adhesion properties of this type of hard coating deposited by magnetron sputtering PVD techniques. To achieve this objective, the deposition process was optimized by combining the nitriding process with magnetron sputtering techniques. Adhesive and tribological properties of great interest were obtained with this technique, such as great toughness and wear resistance and improved adhesion between the coating and the substrate. Our analysis of the results obtained from the experimental procedure yielded the following conclusions:

- The ultra-microhardness of the coatings was about 8.5-10 GPa for all the coated samples, with the higher values obtained for the duplex ones.

- Coefficient of friction (COF) values of around 0.65 were shown by all the specimens, something that can be explained because this coating is not a tribological coating but a hard coating.

- Duplex-coated samples presented greater toughness than the non-nitrided PVD-coated sample, since the $\mathrm{HU}^{3} / \mathrm{Er}^{2}$ ratio, which is associated with the resistance to plastic deformation, and CPR, which is related to the resistance to crack propagation, values are higher for those samples. This is correlated with a greater resistance to wear of those samples, which is a sign that hardness is not the only important parameter in determining the wear behavior of coatings.

- The coatings improved the wear resistance of the substrate considerably, though the best results were obtained for the duplex-coated samples.

- The coatings showed a great adhesion to the substrate, with Lc2 values up to $75 \mathrm{~N}$ for the PVD-coated sample and $96 \mathrm{~N}$ and $109 \mathrm{~N}$ for the duplex-treated 1.2379 and Vanadis 4 samples, respectively. This shows that the combination of the nitriding process with the bonding layer deposited by HiPIMS and the DCMS-deposited layers improves the adhesion properties of these coatings.

- Differences between the different substrates were observed, with greater adhesive and mechanical properties shown by the powder metallurgical steel compared with the conventional steel. This could be because of the higher quality of these steels.

The duplex treatment, which is a combination of the nitriding process with the HiPIMS and DCMS PVD techniques, showed great results, where the improvement in toughness and adhesion can be highlighted. Moreover, these results show that this type of coating technique could be used in the most extreme and demanding applications and competes with other techniques and coatings that to date it has not been able to compete with.

Author Contributions: Conceptualization, J.A.G., A.C., J.J.R. and J.F.P.; formal analysis, J.A.G., J.J.R. and A.C.; investigation, J.J.R., A.C., J.A.G., J.F.P., J.F.d.A. and E.A.; resources, F.M., C.C. and V.C.; writing-original draft preparation, A.C. and J.A.G.; writing—review and editing, A.C., J.A.G., J.F.P., J.F.d.A., E.A., F.M., C.C. and V.C.; supervision, J.A.G.; project administration, J.A.G.; funding acquisition, J.A.G. and J.F.P. All authors have read and agreed to the published version of the manuscript. 
Funding: This research was funded in part by the Spanish Ministry of Science, Innovation and Universities through grants PGC2018-096855-B-C43 and PGC2018-096855-A-C44.

Acknowledgments: The authors acknowledge Tratamientos Termicos Carreras SA (Grup TTC) for their help with the thermochemical treatments. AIN acknowledges the support of the CDTI Ministerio de Ciencia e Innovación of Spain through the project CERVERA (CER2019-1003).

Conflicts of Interest: The authors declare no conflict of interest.

\section{References}

1. Deng, Y.; Tan, C.; Wang, Y.; Chen, L.; Cai, P.; Kuang, T.; Lei, S.; Zhou, K. Effects of tailored nitriding layers on comprehensive properties of duplex plasma-treated AlTiN coatings. Ceram. Int. 2017, 43, 8721-8729. [CrossRef]

2. Musil, J. Hard and superhard nanocomposite coatings. Surf. Coat. Technol. 2000, 125, 322-330. [CrossRef]

3. Lousa, A.; Romero, J.; Martínez, E.; Esteve, J.; Montalà, F.; Carreras, L. Multilayered chromium/chromium nitride coatings for use in pressure die-casting. Surf. Coat. Technol. 2001, 146-147, 268-273. [CrossRef]

4. Chen, W.; Zheng, J.; Meng, X.; Kwon, S.; Zhang, S. Investigation on microstructures and mechanical properties of AlCrN coatings deposited on the surface of plasma nitrocarburized cool-work tool steels. Vacuum 2015, 121, 194-201. [CrossRef]

5. Gilewicz, A.; Jedrzejewski, R.; Myslinski, P.; Warcholinski, B. Structure, Morphology, and Mechanical Properties of AlCrN Coatings Deposited by Cathodic Arc Evaporation. J. Mater. Eng. Perform. 2019, 28, 1522-1531. [CrossRef]

6. Ramírez-Reyna, F.O.; Rodríguez-Castro, G.A.; Figueroa-López, U.; Morón, R.C.; Arzate-Vázquez, I.; Meneses-Amador, A. Effect of nitriding pretreatment on adhesion and tribological properties of AlCrN coating. Mater. Lett. 2021, 284, 128931. [CrossRef]

7. Geng, D.; Zeng, R.; Wu, Z.; Wang, Q. An investigation on microstructure and milling performance of arc-evaporated TiSin/AlTiN film. Thin Solid Film. 2020, 709, 138243. [CrossRef]

8. PalDey, S.; Deevi, S.C. Single layer and multilayer wear resistant coatings of (Ti,Al)N: A review. Mater. Sci. Eng. A 2003, 342, 58-79. [CrossRef]

9. Marchin, N.; Ashrafizadeh, F. Effect of carbon addition on tribological performance of TiSiN coatings produced by cathodic arc physical vapour deposition. Surf. Coat. Technol. 2021, 407, 126781. [CrossRef]

10. Chim, Y.C.; Ding, X.Z.; Zeng, X.T.; Zhang, S. Oxidation resistance of TiN, CrN, TiAlN and CrAlN coatings deposited by lateral rotating cathode arc. Thin Solid Film. 2009, 517, 4845-4849. [CrossRef]

11. Panjan, P.; Navinšek, B.; Cvelbar, A.; Zalar, A.; Milošev, I. Oxidation of TiN, ZrN, TiZrN, CrN, TiCrN and TiN/CrN multilayer hard coatings reactively sputtered at low temperature. Thin Solid Film. 1996, 281-282, 298-301. [CrossRef]

12. Sreejith, P.S.; Ngoi, B.K.A. Dry machining: Machining of the future. J. Mater. Process. Technol. 2000, 101, 287-291. [CrossRef]

13. Kalss, W.; Reiter, A.; Derflinger, V.; Gey, C.; Endrino, J.L. Modern coatings in high performance cutting applications. Int. J. Refract. Met. Hard Mater. 2006, 24, 399-404. [CrossRef]

14. Koseki, S.; Inoue, K.; Morito, S.; Ohba, T.; Usuki, H. Comparison of TiN-coated tools using CVD and PVD processes during continuous cutting of Ni-based superalloys. Surf. Coat. Technol. 2015, 283, 353-363. [CrossRef]

15. Peng, Y.H.; Chen, L.; Xu, Y.X.; Hu, C.; Du, Y. Interface enhanced mechanical and thermal properties of TiSiN/TiAlN multilayers. J. Alloys Compd. 2021, 861, 158571. [CrossRef]

16. Ichimura, H.; Kawana, A. High-temperature oxidation of ion-plated TiN and TiAlN films. J. Mater. Res. 1993, 8, 1093-1100. [CrossRef]

17. Wiesing, M.; de los Arcos, T.; Grundmeier, G. The Thermal Oxidation of TiAlN High Power Pulsed Magnetron Sputtering Hard Coatings as Revealed by Combined Ion and Electron Spectroscopy. Adv. Mater. Interfaces 2017, 4, 1600861. [CrossRef]

18. McIntyre, D.; Greene, J.E.; Håkansson, G.; Sundgren, J.E.; Münz, W.D. Oxidation of metastable single-phase polycrystalline Ti ${ }_{0.5} \mathrm{Al}_{0.5} \mathrm{~N}$ films: Kinetics and mechanisms. J. Appl. Phys. 1990, 67, 1542-1553. [CrossRef]

19. Wu, Z.T.; Sun, P.; Qi, Z.B.; Wei, B.B.; Wang, Z.C. High temperature oxidation behavior and wear resistance of $\mathrm{Ti}_{0.53} \mathrm{Al}_{0.47} \mathrm{~N}$ coating by cathodic arc evaporation. Vacuum 2017, 135, 34-43. [CrossRef]

20. Qi, Z.B.; Sun, P.; Zhu, F.P.; Wu, Z.T.; Liu, B.; Wang, Z.C.; Peng, D.L.; Wu, C.H. Relationship between tribological properties and oxidation behavior of $\mathrm{Ti}_{0.34} \mathrm{Al}_{0.66} \mathrm{~N}$ coatings at elevated temperature up to $900{ }^{\circ} \mathrm{C}$. Surf. Coat. Technol. 2013, 231, $267-272$. [CrossRef]

21. Ma, H.; Miao, Q.; Zhang, G.; Liang, W.; Wang, Y.; Sun, Z.; Lin, H. The influence of multilayer structure on mechanical behavior of TiN/TiAlSiN multilayer coating. Ceram. Int. 2021, 47, 12583-12591. [CrossRef]

22. Lü, W.; Li, G.; Zhou, Y.; Liu, S.; Wang, K.; Wang, Q. Effect of high hardness and adhesion of gradient TiAlSiN coating on cutting performance of titanium alloy. J. Alloys Compd. 2020, 820, 153137. [CrossRef]

23. Li, G.; Sun, J.; Xu, Y.; Xu, Y.; Gu, J.; Wang, L.; Huang, K.; Liu, K.; Li, L. Microstructure, mechanical properties, and cutting performance of TiAlSiN multilayer coatings prepared by HiPIMS. Surf. Coat. Technol. 2018, 353, 274-281. [CrossRef]

24. Chang, C.L.; Chen, W.C.; Tsai, P.C.; Ho, W.Y.; Wang, D.Y. Characteristics and performance of TiSiN/TiAlN multilayers coating synthesized by cathodic arc plasma evaporation. Surf. Coat. Technol. 2007, 202, 987-992. [CrossRef]

25. Yu, D.; Wang, C.; Cheng, X.; Zhang, F. Microstructure and properties of TiAlSiN coatings prepared by hybrid PVD technology. Thin Solid Film. 2009, 517, 4950-4955. [CrossRef] 
26. Chen, L.; Xu, Y.X.; Du, Y.; Liu, Y. Effect of bilayer period on structure, mechanical and thermal properties of TiAlN/AlTiN multilayer coatings. Thin Solid Film. 2015, 592, 207-214. [CrossRef]

27. Chen, L.; Wang, S.Q.; Du, Y.; Zhou, S.Z.; Gang, T.; Fen, J.C.; Chang, K.K.; Li, Y.W.; Xiong, X. Machining performance of Ti-Al-Si-N coated inserts. Surf. Coat. Technol. 2010, 205, 582-586. [CrossRef]

28. Tan, C.; Zhou, K.; Kuang, T.; Li, Y.; Ma, W. Novel performances of in situ plasma nitriding-PVD duplex-treated nanocrystalline TiN coatings. Surf. Eng. 2018, 34, 520-526. [CrossRef]

29. Lee, S.Y. Mechanical properties of TiNx/Cr1-xN thin films on plasma nitriding-assisted AISI H13 steel. Surf. Coat. Technol. 2005, 193, 55-59. [CrossRef]

30. Hoy, R.; Kamminga, J.D.; Janssen, G.C.A.M. Scratch resistance of CrN coatings on nitrided steel. Surf. Coat. Technol. 2006, 200, 3856-3860. [CrossRef]

31. Khlifi, K.; Ben Cheikh Larbi, A. Investigation of adhesion of PVD coatings using various approaches. Surf. Eng. 2013, 29, 555-560. [CrossRef]

32. Barshilia, H.C.; Prakash, M.S.; Jain, A.; Rajam, K.S. Structure, hardness and thermal stability of TiAlN and nanolayered TiAlN/CrN multilayer films. Vacuum 2005, 77, 169-179. [CrossRef]

33. Barshilia, H.C.; Rajam, K.S. Raman spectroscopy studies on the thermal stability of TiN, CrN, TiAIN coatings and nanolayered TiN/CrN, TiAIN/CrN multilayer coatings. J. Mater. Res. 2004, 19, 3196-3205. [CrossRef]

34. Kang, G.H.; Uchida, H.; Koh, E.S. A study on the surface structure of Ti cathode and the macroparticle of TiN films prepared by the arc ion plating process. Surf. Coat. Technol. 1996, 86-87, 421-424. [CrossRef]

35. Ljungcrantz, H.; Hultman, L.; Sundgren, J.E.; Håkansson, G.; Karlsson, L. Microstructural investigation of droplets in arcevaporated TiN films. Surf. Coat. Technol. 1994, 63, 123-128. [CrossRef]

36. Gui, B.; Zhou, H.; Zheng, J.; Liu, X.; Feng, X.; Zhang, Y.; Yang, L. Microstructure and properties of TiAlCrN ceramic coatings deposited by hybrid HiPIMS/DC magnetron co-sputtering. Ceram. Int. 2020, 47, 8175-8183. [CrossRef]

37. Zhang, Q.; Wu, Z.; Xu, Y.X.; Wang, Q.; Chen, L.; Kim, K.H. Improving the mechanical and anti-wear properties of AlTiN coatings by the hybrid arc and sputtering deposition. Surf. Coat. Technol. 2019, 378, 125022. [CrossRef]

38. Bell, T.; Dong, H.; Sun, Y. Realising the potential of duplex surface engineering. Tribol. Int. 1998, 31, 127-137. [CrossRef]

39. Das, K.; Alphonsa, J.; Ghosh, M.; Ghanshyam, J.; Rane, R.; Mukherjee, S. Influence of pretreatment on surface behavior of duplex plasma treated AISI H13 tool steel. Surf. Interfaces 2017, 8, 206-213. [CrossRef]

40. Zeghni, A.E.; Hashmi, M.S.J. The effect of coating and nitriding on the wear behaviour of tool steels. J. Mater. Process. Technol. 2004, 155-156, 1918-1922. [CrossRef]

41. Zheng, J.; Zhang, S.H.; Wu, P.; Kwon, S.C.; Li, M.X.; Liu, S.Y.; Chen, W.L. Microstructures and mechanical properties of duplex-treated composite ceramic coatings with and without compound layer. Ceram. Int. 2015, 41, 2519-2526. [CrossRef]

42. Yang, S.; Cooke, K.; Sun, H.; Li, X.; Lin, K.; Dong, H. Development of advanced duplex surface systems by combining CrAlN multilayer coatings with plasma nitrided steel substrates. Surf. Coat. Technol. 2013, 236, 2-7. [CrossRef]

43. Björk, T.; Westergård, R.; Hogmark, S.; Bergström, J.; Hedenqvist, P. Physical vapour deposition duplex coatings for aluminium extrusion dies. Wear 1999, 225-229, 1123-1130. [CrossRef]

44. Dong, H.; Sun, Y.; Bell, T. Enhanced corrosion resistance of duplex coatings. Surf. Coat. Technol. 1997, 90, 91-101. [CrossRef]

45. Harris, S.G.; Doyle, E.D.; Vlasveld, A.C.; Dolder, P.J. Dry cutting performance of partially filtered arc deposition titanium aluminium nitride coatings with various metal nitride base coatings. Surf. Coat. Technol. 2001, 146-147, 305-311. [CrossRef]

46. Podgornik, B.; Vižintin, J.; Wänstrand, O.; Larsson, M.; Hogmark, S.; Ronkainen, H.; Holmberg, K. Tribology properties of plasma nitrided and hard coated AISI 4140 steel. Wear 2001, 249, 254-259. [CrossRef]

47. Torres, R.D.; Soares, P.C.; Schmitz, C.; Siqueira, C.J.M. Influence of the nitriding and TiAlN/TiN coating thickness on the sliding wear behavior of duplex treated AISI H13 steel. Surf. Coat. Technol. 2010, 205, 1381-1385. [CrossRef]

48. Tillmann, W.; Grisales, D.; Stangier, D. Effects of AISI H11 surface integrity on the residual stresses and adhesion of TiAlN/substrate compounds. Surf. Coat. Technol. 2019, 357, 466-472. [CrossRef]

49. Tillmann, W.; Vogli, E.; Momeni, S. Improvement of press dies used for the production of diamond composites by means of DUPLEX-PVD-coatings. Surf. Coat. Technol. 2010, 205, 1571-1577. [CrossRef]

50. Sprute, T.; Tillmann, W.; Grisales, D.; Selvadurai, U.; Fischer, G. Influence of substrate pre-treatments on residual stresses and tribo-mechanical properties of TiAlN-based PVD coatings. Surf. Coat. Technol. 2014, 260, 369-379. [CrossRef]

51. Park, B.; Jung, D.H.; Kim, H.; Yoo, K.C.; Lee, J.J.; Joo, J. Adhesion properties of $\mathrm{TiB}_{2}$ coatings on nitrided AISI H13 steel. Surf. Coat. Technol. 2005, 200, 726-729. [CrossRef]

52. Claver, A.; Jiménez-Piqué, E.; Palacio, J.F.; Almandoz, E.; Fernández de Ara, J.; Fernández, I.; Santiago, J.A.; Barba, E.; García, J.A. Comparative Study of Tribomechanical Properties of HiPIMS with Positive Pulses DLC Coatings on Different Tools Steels. Coatings 2020, 11, 28. [CrossRef]

53. Akhter, R.; Zhou, Z.; Xie, Z.; Munroe, P. Enhancing the adhesion strength and wear resistance of nanostructured NiCrN coatings. Appl. Surf. Sci. 2021, 541, 148533. [CrossRef]

54. Chen, W.; Fang, B.; Zhang, D.; Meng, X.; Zhang, S. Thermal stability and mechanical properties of HVOF/PVD duplex ceramic coatings produced by HVOF and cathodic vacuum arc. Ceram. Int. 2017, 43, 7415-7423. [CrossRef]

55. Toboła, D.; Brostow, W.; Czechowski, K.; Rusek, P. Improvement of wear resistance of some cold working tool steels. Wear 2017, 382-383, 29-39. [CrossRef] 
56. García, J.A.; Rodríguez, R.J.; Martínez, R.; Fernández, C.; Fernández, A.; Payling, R. Depth profiling of industrial surface treatments by rf and dc glow discharge spectrometry. Appl. Surf. Sci. 2004, 235, 97-102. [CrossRef]

57. Chen, W.; Zheng, J.; Lin, Y.; Kwon, S.; Zhang, S. Comparison of AlCrN and AlCrTiSiN coatings deposited on the surface of plasma nitrocarburized high carbon steels. Appl. Surf. Sci. 2015, 332, 525-532. [CrossRef]

58. ASTM International. G99-17 Standard Test Method for Wear Testing with a Pin-on-Disk Apparatus; ASTM International: West Conshohocken, PA, USA, 2017; Available online: https:/ / www.astm.org (accessed on 23 September 2021).

59. Charitidis, C.A. Nanomechanical and nanotribological properties of carbon-based thin films: A review. Int. J. Refract. Met. Hard Mater. 2010, 28, 51-70. [CrossRef]

60. Galvan, D.; Pei, Y.T.; De Hosson, J.T.M. Deformation and failure mechanism of nano-composite coatings under nano-indentation. Surf. Coat. Technol. 2006, 200, 6718-6726. [CrossRef]

61. Sha, C.; Zhou, Z.; Xie, Z.; Munroe, P. Scratch response and tribological behaviour of CrAlNiN coatings deposited by closed field unbalanced magnetron sputtering system. Surf. Coat. Technol. 2019, 367, 30-40. [CrossRef]

62. Leyland, A.; Matthews, A. On the significance of the H/E ratio in wear control: A nanocomposite coating approach to optimised tribological behaviour. Wear 2000, 246, 1-11. [CrossRef]

63. Zhang, S.; Sun, D.; Fu, Y.; Du, H. Effect of sputtering target power on microstructure and mechanical properties of nanocomposite nc-TiN/a-SiNx thin films. Thin Solid Film. 2004, 447-448, 462-467. [CrossRef]

64. He, J.; Lan, X.; Wan, J.; Liu, H.; Liu, Z.; Jiao, D.; Zhong, X.; Cheng, Y.; Qiu, W. Modifying Cr/CrN composite structure by Fe addition: Toward manufacturing cost-effective and tough hard coatings. Appl. Surf. Sci. 2021, 545, 149025. [CrossRef]

65. Cai, F.; Zhang, S.; Li, J.; Chen, Z.; Li, M.; Wang, L. Effect of nitrogen partial pressure on Al-Ti-N films deposited by arc ion plating. Appl. Surf. Sci. 2011, 258, 1819-1825. [CrossRef]

66. Warcholinski, B.; Gilewicz, A.; Myslinski, P.; Dobruchowska, E.; Murzynski, D. Structure and properties of AlCrN coatings deposited using cathodic arc evaporation. Coatings 2020, 10, 793. [CrossRef]

67. Al-Bukhaiti, M.A.; Al-Hatab, K.A.; Tillmann, W.; Hoffmann, F.; Sprute, T. Tribological and mechanical properties of Ti/TiAlN/TiAlCN nanoscale multilayer PVD coatings deposited on AISI H11 hot work tool steel. Appl. Surf. Sci. 2014, 318, 180-190. [CrossRef]

68. Kumar, S.; Maity, S.R.; Patnaik, L. Friction and tribological behavior of bare nitrided, TiAlN and AlCrN coated MDC-K hot work tool steel. Ceram. Int. 2020, 46, 17280-17294. [CrossRef]

69. Myśliński, P.; Szparaga, Ł.; Gilewicz, A.; Mydłowska, K.; Piątkowska, A. Investigations of the thermo-mechanical stability of hybrid layers for tribological applications: Nitrided layer/CrCN coating system. Vacuum 2018, 148, 276-285. [CrossRef]

70. Candido Recco, A.A.; Tschiptschin, A.P. Structural and mechanical characterization of duplex multilayer coatings deposited onto H13 tool steel. J. Mater. Res. Technol. 2012, 1, 182-188. [CrossRef]

71. Kumar, C.S.; Patel, S.K. Performance analysis and comparative assessment of nano-composite TiAlSiN/TiSiN/TiAlN coating in hard turning of AISI 52100 steel. Surf. Coat. Technol. 2018, 335, 265-279. [CrossRef]

72. Tan, C.; Kuang, T.; Zhou, K.; Zhu, H.; Deng, Y.; Li, X.; Cai, P.; Liu, Z. Fabrication and characterization of in-situ duplex plasma-treated nanocrystalline Ti/AlTiN coatings. Ceram. Int. 2016, 42, 10793-10800. [CrossRef]

73. Novák, P.; Vojtěch, D.; Šerák, J. Wear and corrosion resistance of a plasma-nitrided PM tool steel alloyed with niobium. Surf. Coat. Technol. 2006, 200, 5229-5236. [CrossRef]

74. Kabir, M.S.; Munroe, P.; Zhou, Z.; Xie, Z. Scratch adhesion and tribological behaviour of graded Cr/CrN/CrTiN coatings synthesized by closed-field unbalanced magnetron sputtering. Wear 2017, 380-381, 163-175. [CrossRef] 